\title{
Diagnosis, Screening and Treatment of Patients with Palmoplantar Pustulosis (PPP): A Review of Current Practices and Recommendations
}

This article was published in the following Dove Press journal: Clinical, Cosmetic and Investigational Dermatology

\author{
Egídio Freitas (D) \\ Maria Alexandra Rodrigues' \\ Tiago Torres (iD) ${ }^{1,2}$ \\ 'Department of Dermatology, Centro \\ Hospitalar e Universitário do Porto, \\ Porto, Portugal; ${ }^{2}$ Instituto de Ciências \\ Biomédicas Abel Salazar, Universidade do \\ Porto, Porto, Portugal
}

\begin{abstract}
Palmoplantar pustulosis (PPP) is a rare, chronic, recurrent inflammatory disease that affects the palms and/or the soles with sterile, erupting pustules, which are debilitating and usually resistant to treatment. It has genetic, histopathologic and clinical features that are not present in psoriasis; thus, it can be classified as a variant of psoriasis or as a separate entity. Smoking and upper respiratory infections have been suggested as main triggers of PPP. PPP is a challenging disease to manage, and the treatment approach involves both topical and systemic therapies, as well as phototherapy and targeted molecules. No gold standard therapy has yet been identified, and none of the treatments are curative. In patients with mild disease, control may be achieved with on-demand occlusion of topical agents. In patients with moderate-to-severe PPP, phototherapy or a classical systemic agent (acitretin being the best treatment option, especially in combination with PUVA) may be effective. Refractory patients or those with contraindications to use these therapies may be good candidates for apremilast or biologic therapy, particularly antiIL-17A and anti-IL-23 agents. Recent PPP trials are focusing on blockage of IL-36 or IL-1 pathways, which play an important role in innate immunity. Indeed, IL-36 isoforms have been strongly implicated in the pathogenesis of psoriasis. Therefore, blockage of the IL-36 pathway has become a new treatment target in PPP, and three studies are currently evaluating the use of monoclonal antibodies that block the IL-36 receptor in PPP: ANB019 and spesolimab (BI 655130). In this review, we explore the diagnosis, screening and treatment of patients with PPP. Keywords: palmoplantar pustulosis, palmoplantar pustulosis psoriasis, IL36, ANB019, spesolimab
\end{abstract}

\section{Introduction}

Palmoplantar pustulosis (PPP) is a chronic inflammatory disease that affects the palms and/or the soles. It is debilitating and usually resistant to treatment. It persists for years with periods of partial or total remission interrupted by recurrent exacerbations. ${ }^{1}$ Its pathogenesis is still poorly understood. Clinically it is defined by eruptions of sterile pustules that appear abruptly on an erythemato-squamous background (it may be associated with hyperkeratosis, erythema, scaling, and fissuring). ${ }^{2}$ It can be classified as a variant of psoriasis or as a separate entity. ${ }^{3}$

PPP is a rare disease, with a prevalence estimated to range from 0.01 to $0.05 \% .{ }^{4}$ It seems to be more frequent among females (at least two thirds of patients, with a percentage that ranges from $65.3 \%$ of patients in a nationwide Japanese database to $94 \%$ in a Swedish study. 5 , It commonly occurs in the fifth or sixth decade of life, with a mean age of onset that varies from 40 to 58 years. ${ }^{4,7}$
Correspondence: Tiago Torres Serviço de Dermatologia Centro Hospitalar do Porto, Rua D. Manuel II, s/n Piso I, Porto 4050-344, Portugal $\mathrm{Tel} / \mathrm{Fax}+35$ I 226097429

Email torres.tiago@outlook.com 
In this review, we explore the diagnosis, screening and treatment of patients with PPP.

\section{Differentiating Palmoplantar Pustulosis (PPP) from Palmoplantar Pustular Psoriasis (PPPP)}

In 1930 Barber described for the first time PPP as a psoriasis subtype, calling it localized palmoplantar pustulosis/Barber type, as opposed to generalized pustular psoriasis/von Zumbusch type (which is defined as a lifethreatening, rare disease with recurrent flares of pustular, erythematous lesions). ${ }^{8}$ The nosological position of PPP remains unclear to this day. PPP can be considered in the clinical spectrum of plaque psoriasis or as an independent disease. The debate is still ongoing. Consequently, in the literature, PPPP and PPP are often not well distinguished. In 2007, the International Psoriasis Council, reclassified PPP as a separate disease. ${ }^{7}$

PPP is a bilateral, symmetric dermatosis that consists of pustular lesions typically limited to the palms and/or soles that appear on an erythemato-squamous background. ${ }^{9}$ (Figures 1-6) Clinically, it is distinguished from PPPP based on the absence of psoriasis at other body sites and a predilection for histologic involvement of the acrosyringium (the terminal duct of eccrine sweat glands), a feature that seems to be more specific to PPP. ${ }^{9}$ PPPP is a psoriasis variant that may affect $11-39 \%$ of psoriasis patients and is characterized by macroscopic sterile pustules intermixed with yellow-brown macules affecting the hands and/or feet. ${ }^{2,10}$ In most cases, PPPP occurs concomitantly with psoriasis at other body areas. Therefore, a complete cutaneous exam is a key step to differentiate the two entities. If lesions are only present in the palms/soles, the term PPP should be used. If, on the other hand, besides the palms/ soles pustulosis, concomitant plaque psoriasis or a positive family history for psoriasis is present, then PPPP should be applied. . $^{3,7}$

Regarding age at onset of disease, disease duration, family history of psoriasis, concomitant arthritis, and cardiovascular disease, no significant differences have been reported between PPP and PPPP in observational studies. ${ }^{7}$ On the other hand, female sex, smoking, and autoimmune thyroid disease seem to be associated with PPP. ${ }^{11,12}$ In fact, the association with smoking is strong, and it is thought that in individuals with PPP, nicotine is secreted into eccrine glands to promote inflammation and alter the local response to infection. ${ }^{9}$ Recent studies have challenged the genetic

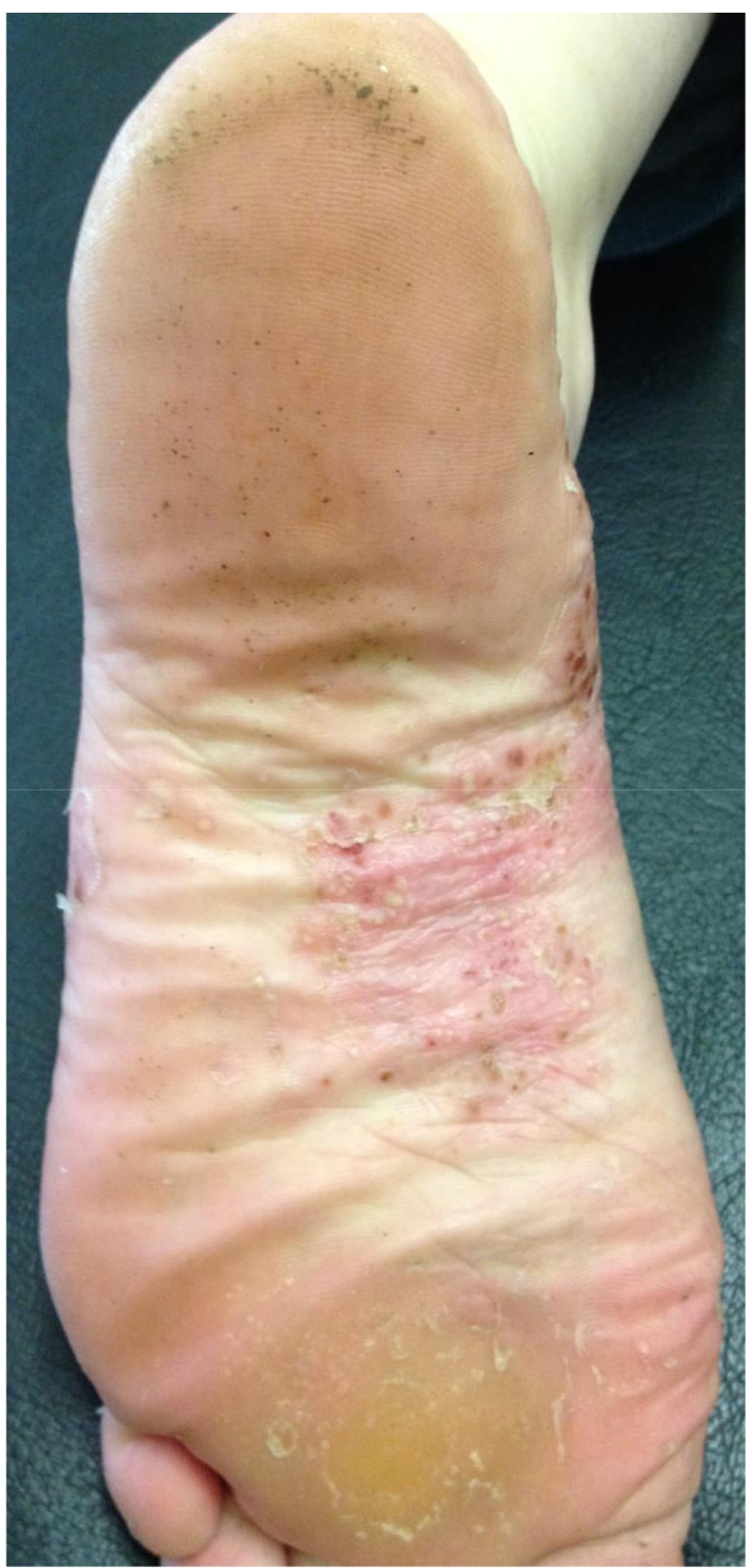

Figure I Scattered pustules on a erythematous base with desquamation on the medial zone of the plantar surface of the foot.

relationship of PPP with plaque psoriasis, although both these entities can respond to similar treatments and have a similar impact on quality of life. Table 1 summarizes the main clinical features of palmoplantar pustular psoriasis and palmoplantar pustulosis.

\section{Genetic Studies}

Data on the genetic risk factors for PPP are limited. International Psoriasis Council declare that PPP should 


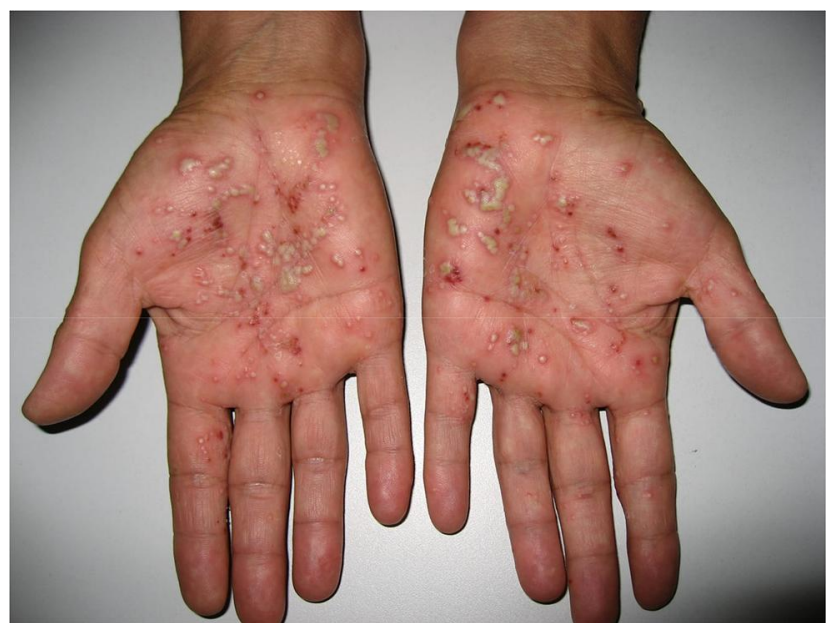

Figure 2 Pustules, sometimes coalescing, with erythematous halo, affecting mainly the palms.

be viewed as an entity independent of psoriasis, mainly due to genetic studies that have not shown an association with the psoriasis susceptibility gene 1 (PSORS 1 ). ${ }^{13}$ Many genetic studies have revealed that PPP may have numerous mutations in the IL36RN, CARD14 and ASP1S3 genes. ${ }^{14}$ Future clinical and genetic studies will be crucial to elucidate whether this diverse genetic profile can affect the response to therapy - i.e, biological. ${ }^{15}$

Studies carried out in patients with generalized pustular psoriasis have found a mutation in IL36RN, and this is considered the most important predisposing factor for generalized pustular psoriasis (GPP) ${ }^{16}$ However, the IL36RN mutation was found only in a low proportion of patients with PPP, and no association was found between the IL36RN mutation and PPP. ${ }^{17}$ More recently, Twelves et al${ }^{17}$ studied the genetic and clinical characteristics of different forms of pustular psoriasis. Loss of- function mutations in IL36RN were present in $5.1 \%$ of patients with PPP. Additionally, it was found that there was a statistically significant association between PPP and IL36RN mutations. Twelves et $\mathrm{al}^{17}$ also suggested that mutations in IL36RN are related to early onset of the disease in all types of pustular psoriasis and that patients with PPP and age $<40$ years should do a screen for mutations in IL36RN. ${ }^{18}$ Therefore, recent studies indicate the role of the mutation of the IL-36 receptor antagonist gene (IL-36RN) in the development of PPP but also in several forms of psoriasis, namely the plaque type, the pustular palmoplantar type and the generalized pustular type. ${ }^{19}$ This finding infers that the interleukin-36 pathway may be implicated in the pathogenesis of this disease. ${ }^{20}$ It has

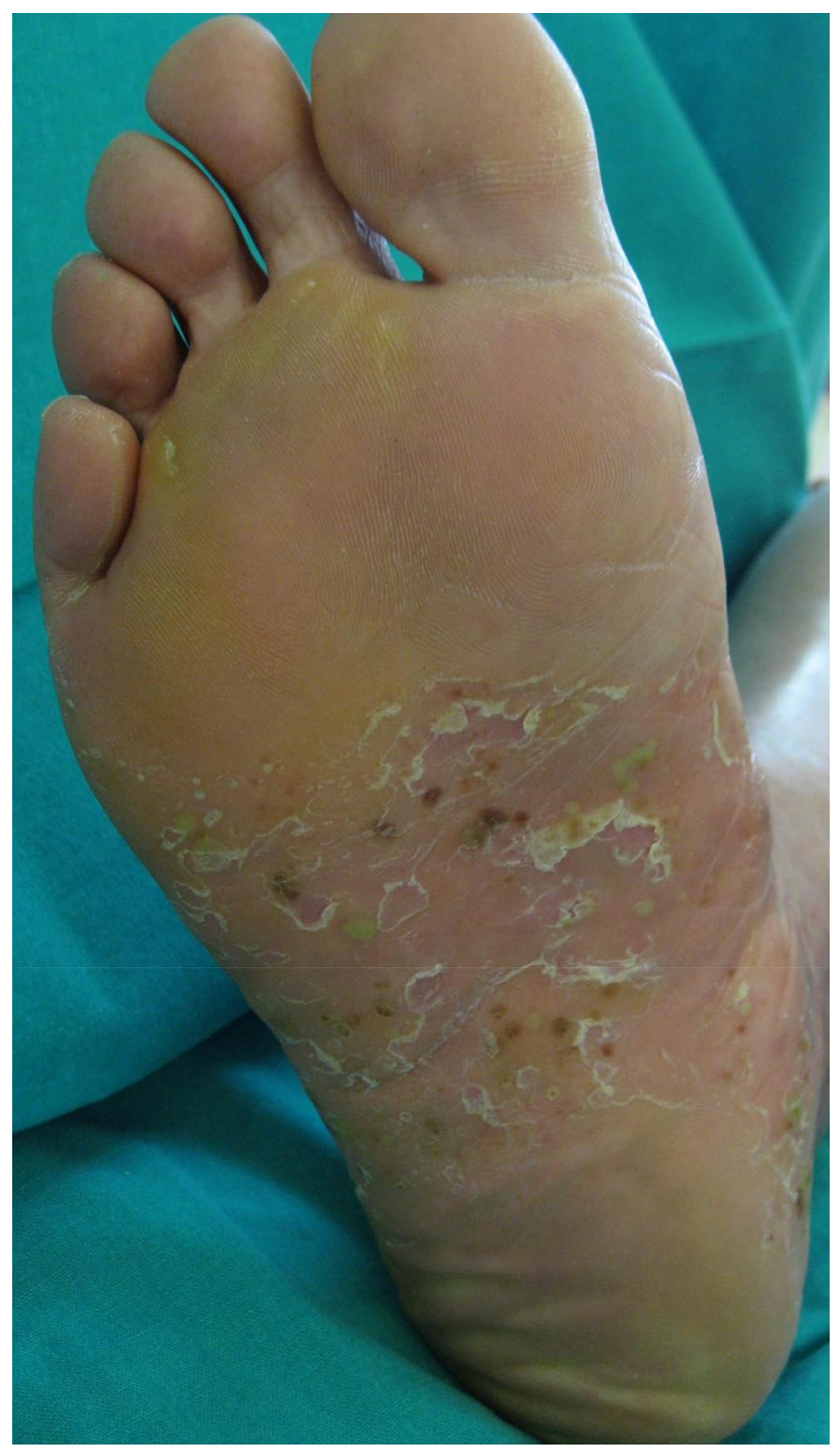

Figure 3 Pustular lesions in a erythematous and scaling plaque affecting the central zone of the plantar surface of the foot.

also been noted that the mutation is the genetic base of the deficiency of the IL-36 receptor antagonist (DITRA), which is a rare autosomal recessive hereditary disorder portrayed by disseminated pustular lesions that resemble acute generalized exanthematous pustulosis (AGEP) or

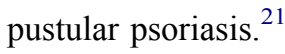

Recent studies have described, in numerous patients with PPP, mutations in CARD14 [family member of the caspase 14 recruiting domain], principally in males and patients without a positive family history of common psoriasis. ${ }^{17}$ Current studies have also shown mutations in AP1S3 in few patients with PPP. ${ }^{17,22}$ Based on the outcomes of the research, the authors proposed that there are overlapping genetic risk factors in psoriasis PPP and generalized pustular psoriasis. ${ }^{22}$ 


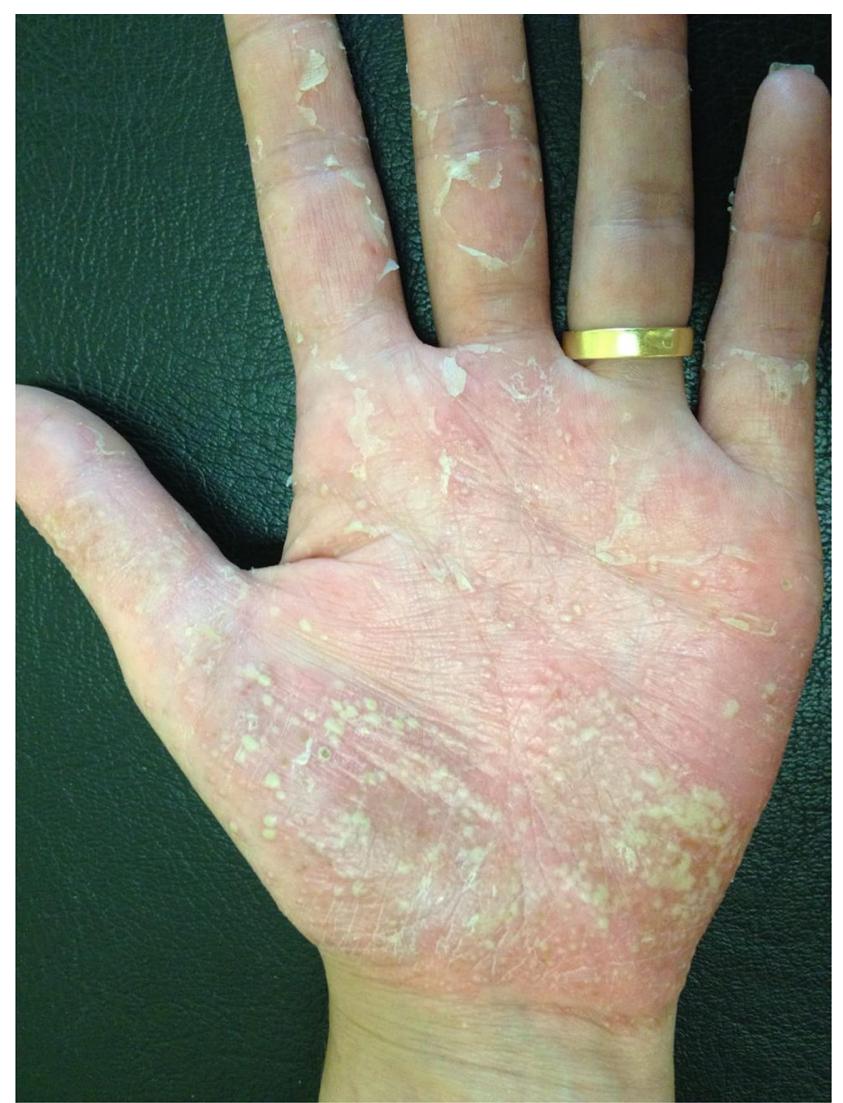

Figure 4 Erythema, multiple pustules and scaling in the palmar surface of the hand.

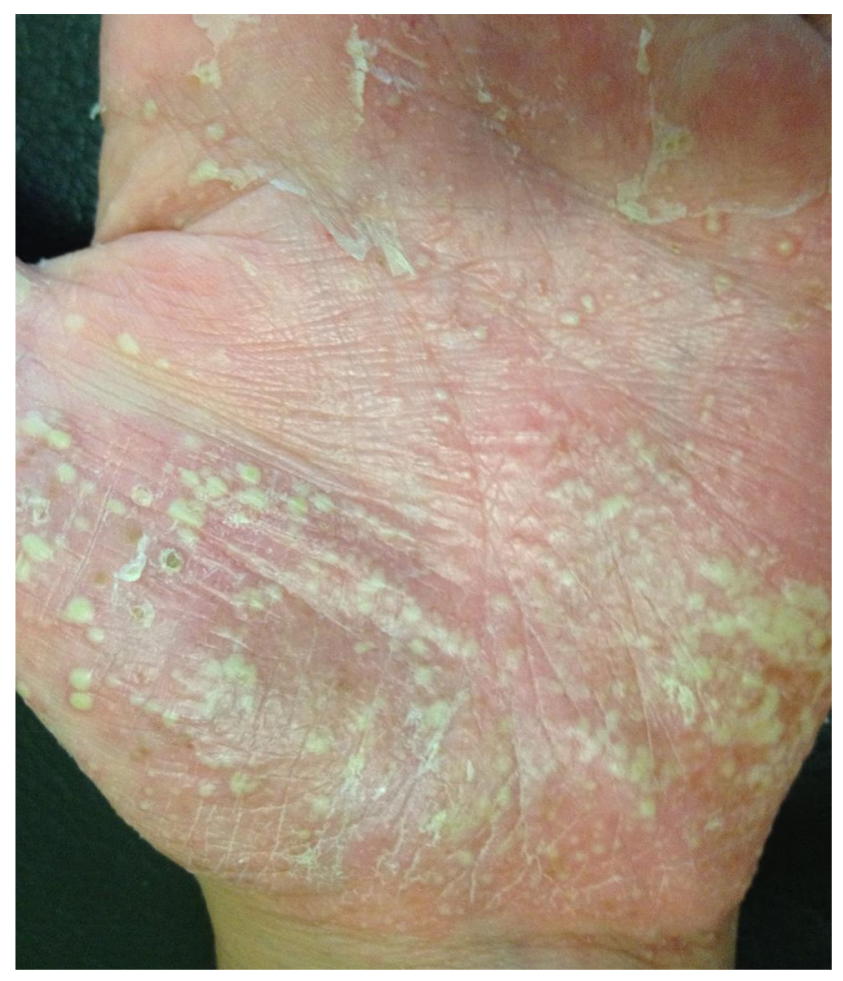

Figure 5 A closer look of Figure 4.

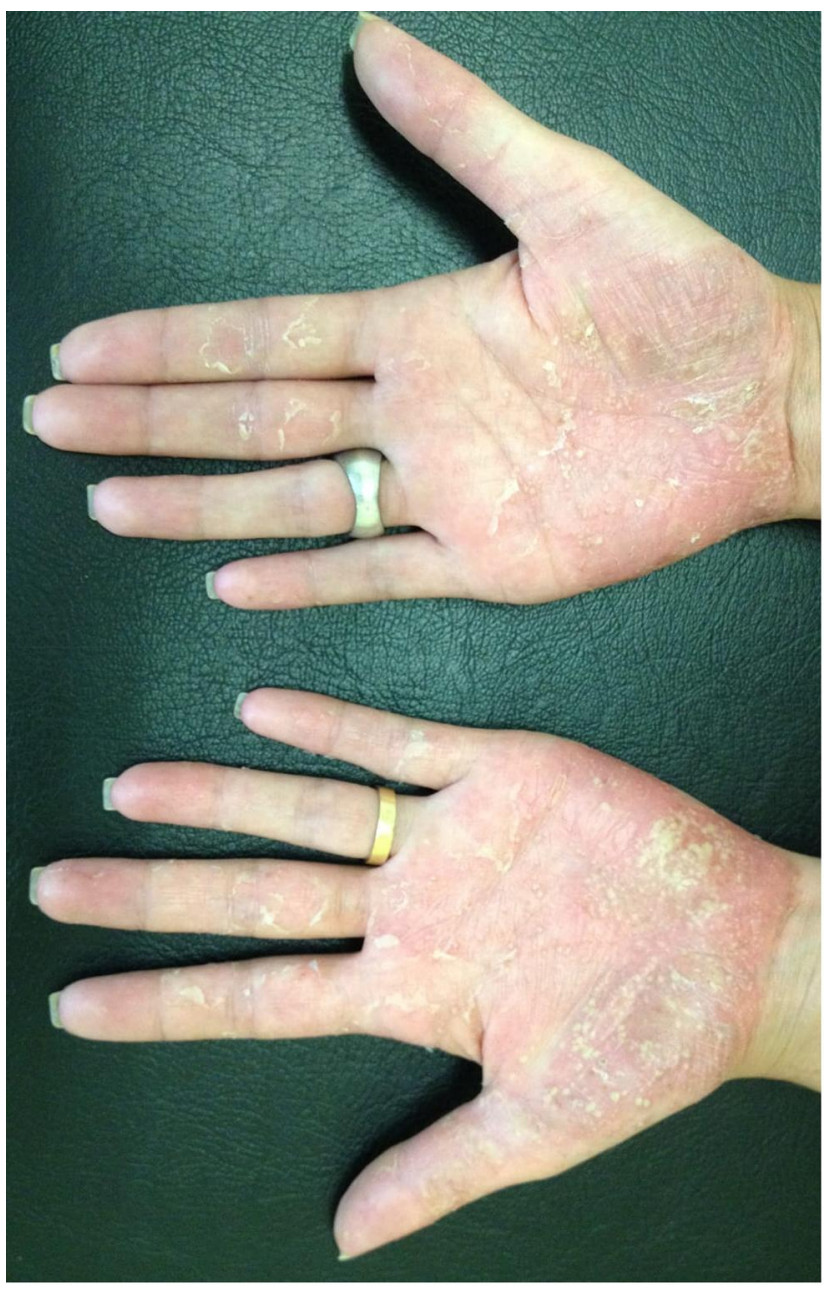

Figure 6 The pustular eruption affecting both palmar surfaces of the hands.

PSORS1 (the most powerful identified genetic risk factor for psoriasis vulgaris) has not been associated with PPP. ${ }^{13}$ Genetic studies of TNF-238 and -308 promoter polymorphisms in PPP revealed no connection between polymorphisms and PPP. ${ }^{23}$

Genomic analyses have identified modified IL19 and IL20 genetic clusters in PPP patients. ${ }^{24}$ Another genetic factor operating a role in psoriasis pathogenesis is ATG16L1 mutation in a gene located on chromosome 2. ATG16L1 plays a role in the immunological response, so mutation of this gene affects the production of antimicrobial peptides and the production of IL-18 and IL-1, leading to a propagating systemic inflammation. Studies reveal that Rs2241879A and rs2241880 G single nucleotide polymorphisms (SNPs) of the ATG16L1 gene are often among patients with PPP contrasted to healthy individuals. ${ }^{25}$ Since there is a coexistence between PPP with arthralgia and arthritis in some patients, the genetic basis of PPP has 
Table I Summarizes the Main Clinical Features of Palmoplantar Pustular Psoriasis and Palmoplantar Pustulosis

\begin{tabular}{|c|c|c|}
\hline & Palmoplantar Pustulosis & Palmoplantar Pustular Psoriasis \\
\hline $\begin{array}{l}\text { Sites of } \\
\text { predilection }\end{array}$ & $\begin{array}{l}\text { Typically limited to the palms and/or soles, but can spread to } \\
\text { the lateral parts of hands and feet }\end{array}$ & $\begin{array}{l}\text { Palms and soles, in most cases, occurs concomitantly with } \\
\text { psoriasis at other body areas }\end{array}$ \\
\hline Skin changes & $\begin{array}{l}\text { Eruptions of sterile pustules that appear abruptly on an } \\
\text { erythemato-squamous background }\end{array}$ & $\begin{array}{l}\text { Well demarcated papules } \\
\text { and patches, massive } \\
\text { hyperkeratosis and scaling intermixed with sterile } \\
\text { pustules }\end{array}$ \\
\hline Nail changes & Onycholysis, pitting subungual, pustules and dystrophy & Onycholysis, pitting subungual, pustules and dystrophy \\
\hline $\begin{array}{l}\text { Associated } \\
\text { conditions }\end{array}$ & $\begin{array}{l}\text { Upper respiratory infections; Psoriatic arthritis; Smoking } \\
\text { Female sex; Thyroid gland dysfunction }\end{array}$ & Psoriatic arthritis \\
\hline $\begin{array}{l}\text { Prevalent } \\
\text { symptoms }\end{array}$ & Pain & Moderate itch \\
\hline $\begin{array}{l}\text { Positive family } \\
\text { history for } \\
\text { psoriasis }\end{array}$ & No & Yes \\
\hline Histology & $\begin{array}{l}\text { Sterile, unilocular (single cavity) intraepidermal pustules filled } \\
\text { with eosinophils and neutrophils located in the } \\
\text { Acrosyringium }\end{array}$ & $\begin{array}{l}\text { Orthokeratosis alternating with many foci of } \\
\text { parakeratosis and the existence of inflammatory cells }\end{array}$ \\
\hline $\begin{array}{l}\text { Genetic } \\
\text { susceptibility }\end{array}$ & CARDI 4 and IL36RN & Psoriasis susceptibility gene I (PSORS I) \\
\hline
\end{tabular}

been connected with that of psoriatic arthritis. A correlation between the HLA-B27 antigen, typical of psoriatic arthritis, and PPP was found. The HLA-B27 antigen was recognized in $32 \%$ of patients with PPP with arthralgia in the hip, in the area of the anterior thorax or peripheral joints. $^{26}$

\section{Etiopathogenesis}

To better understand the inflammatory pathways (cytokines and inflammatory cells) involved in PPP, several immunohistochemical investigations were conducted, providing data for more in-depth knowledge of the disease and the future setting up of a personalized treatment regimen. $^{27}$

\section{Acrosyringia}

Acrosyringium is an immunocompetent structure with a significant role in the barrier function and in the defense of the skin. ${ }^{27}$ Current studies indicate that acrosyringium performs a important role in the inflammatory process of PPP. $^{3}$ Several pathophysiologic and histologic studies have shown that this inflammatory process begins in the acrosyringia, leading posteriorly to their destruction. $4,28,29$
The cholinergic system is responsible for innervating the sweat glands and acetylcholine (Ach) is the main inducer of sweating. Acetylcholine functions through 2 types of receptors: nicotinic (nAchR) and muscarinic (mAchR). The level of Ach is controlled by Ach nicotinic transferase and this can affect the sweat glands functions. Studies have revealed that the cholinergic system is implicated in the inflammatory process, with alterations in the expression of enzymes: acetylcholinesterase and choline acetyltransferase and nicotinic acetylcholine receptors in the skin of PPP patients. ${ }^{30}$ It has been demonstrated, due to the fact that there are large amounts of esterase in the lower layers of the acrosiringium in patients with PPP, that the Ach level is lower, as the esterase decompose the neurotransmitter. Nicotine binds to nAch receptors in the absence of Ach. It is believed that the activation of nicotine Ach receptors by nicotine and not by Ach may play a role in PPP pathogenesis, as it leads to the accumulation of eosinophils and neutrophils, and consequently, to the formation of pustules. In addition, nicotine likewise affects the keratinocytes nearby the sweat glands and causes increased keratosis of the excretory ducts. ${ }^{27,31}$ In fact, an association has been described between the cholinergic system and nicotine that appears to be based on the 
nicotine excretion in the eccrine ducts. Thus, nicotine seems to alter the expression of antigens in the acrosyringium, pulling Langerhans cells and provoke the production of IL-17 in the soles of the feet and palms. ${ }^{27}$

\section{The IL23/I 7 Pathway}

The immunological processes involved in PPP, lead to the accumulation, in the area of the the acrosyringium, of a substantial quantity of granulocytes. ${ }^{27,31}$ The cytokines that regulate these processes play a fundamental role. As in psoriasis, in PPP, there is also an increase in the levels of proinflammatory interleukins in blood such as TNF- $\alpha$, IL-22, IL17 and gamma interferon (IFN- $\gamma$ ). ${ }^{32}$ However, differences were found in interleukins produced in psoriatic lesions and PPP. In psoriatic lesions, large amounts of cytokines are produced by Th17 lymphocytes (IL-17, IL-12 and IL-23), while in PPP only a significant increase in IL-17 expression occurred, without concomitant elevation of IL-23 and IL-12. ${ }^{33}$ These data corroborate the opinion that IL-17 plays a meaningful role in PPP expression, which is evidence of significant interest, given the availability of an extensive spectrum of biologic agents targeting IL-17. ${ }^{34}$ Elevated IL-17 in the epidermis stimulates the production of IL- 6 by keratinocytes, activating monocytes and neutrophils and attracting granulocytes to the epidermis, leading to the formation of pustules. In this way, interleukin 6 plays a fundamental role in the formation of the pustule as seen in PPP. Patients show increased levels of this cytokine in both skin lesions and blood. ${ }^{35}$ Interleukin 6 is part of the gp130 cytokine family and is a pro-inflammatory cytokine. ${ }^{36}$ It stimulates the production of acute phase proteins, differentiation and cell $T$ activation, differentiation of $B$ cells into mature cells, activation of Th17 lymphocytes and also other non-immune cells, such as fibroblasts and keratinocytes. ${ }^{36}$ Furthermore, it stimulates macrophages to generate chemokines, for example, monocyte chemotactic protein 1 (MCP-1) and IL-8, and it leads to production of adhesion molecules in the vascular endothelium, leading to increased granulocyte migration and consequent to the formation of pustules. ${ }^{37}$ Thus, IL-6 appears to be an excellent new target in PPP treatment. ${ }^{38}$

\section{IL-8 and IL-36 Pathway}

IL-36 interleukins have been strongly implicated in the pathogenesis of psoriasis. It is thought that they exhibit their effects through activation of dendritic cells that can promote the T helper 17 (Th17) phenotype, a key player in this disease. ${ }^{39}$ IL-17 production by the Th17 cells may also increase IL-36 expression, creating a feedback loop that drives inflammation and disease. ${ }^{40}$ It has been hypothesized that this mechanism would explain the spectrum of disease, with localized activation causing Th17dependent overexpression of IL-36 cytokines in plaque psoriasis, and systemic activation causing the more severe disease generalized pustular psoriasis (GPP). ${ }^{41}$ Mutations in IL-36RN, which results in a misfolded IL-36Ra that disables its interaction with IL-36R, can cause the rare, life-threatening disease, GPP. ${ }^{42}$ GPP presents with suddenonset high-grade fever, generalized rash with disseminated pustules, elevated leukocyte count, and elevated C-reactive protein serum levels. ${ }^{16}$ Deficiency of IL-36Ra causes an increase in the severity of the lesions in the epidermis. ${ }^{16}$

Regarding PPP patients, studies have shown upregulation of IL-8 messenger RNA (mRNA) in the lesional skin and the expression to be upregulated by LL-37, the mature form of cathelicidin. ${ }^{43}$ IL-8 is seen as a potent chemoattractant and activator of neutrophils and a major player inducing pustule formation. The expression of IL-8, IL$36 \gamma$, and IL-36Ra has been evaluated in patients with PPP. $^{44}$ IL- $36 \gamma$ is part of the IL-1 family and stimulates keratinocytes to produce IL-8. IL-36Ra, encoded by

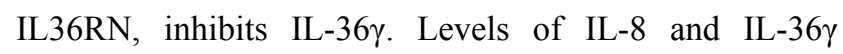
mRNA and protein were shown to be significantly increased in PPP lesional skin compared with healthy subjects. IL-36Ra mRNA was markedly overexpressed in PPP lesions compared with healthy skin, but IL-36Ra protein expression did not differ between PPP, psoriasis

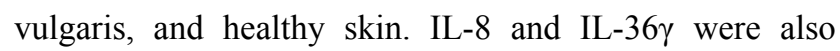
shown to be related to acrosyringia in pustule formation. ${ }^{44}$ Blockage of the IL-36 pathway has become a new treatment target in PPP, and studies of the use of monoclonal antibodies against the IL-36 receptor are ongoing. Moreover, an ongoing phase IIa trial is studying the role of RIST4721/AZD4721, which blocks CXCR2, in PPP. CXCR2 (IL-8 receptor type B) mediates the action of IL- $8 .{ }^{45}$

\section{Lipocalin 2}

Studies have discovered that patients with PPP had high levels of lipocalin 2 in the blood. ${ }^{46}$ This increase was mainly regulated by IL- $1 \beta$. Wolk et $\mathrm{al}^{46}$ also reports a significant positive correlation between pustule score and lipocalin 2 levels. In conclusion, the studies cited above show that the innate immune response plays a central role in the PPP pathophysiology and be more important than in psoriasis vulgaris. 


\section{Microbiome}

Recently published studies explore the microbiome in patients with PPP. Masuda-Kuroki et $\mathrm{al}^{47}$ showed that vesicopustules of PPP patients had a microbiome. Bacteria were detected in $30.2 \%$ of the pustulovesicles. Through the phylum level analysis, Proteobacteria, Firmicutes, Bacteroidetes, and Actinobacteria were the most abundant bacteria found. In a gender analysis, in pustulovesicles, Devosia, Staphylococcus, and Pseudonocardia were the most relatively plentiful bacteria. A significant difference was identified in the abundance of Staphylococcus between non-smokers and smokers with PPP, with more bacteria detected in smokers. ${ }^{47}$ The outcomes of these investigations show that although the pustules in PPP are "sterile" in the sense that they are "non infective, non contagious" they still may have a microbiome. Instead of using culture methods, recent studies used amplification and sequencing of bacterial ribosomal RNA genes to bacteria detection. This technique has the benefit of being capable of identifying dead bacteria and those that cannot be raised under laboratory conditions. ${ }^{47}$

\section{Clinical Presentation}

PPP manifests clinically as sterile, erupting pustules, located on the palms and soles (it can also affect the lateral portions of feet and hands), with a chronic and cyclic course, occurring on a desquamative and erythematous background and are usually symmetrical. ${ }^{4}$ The lesions develop in abundant eccrine sweat glands affluent areas, which probably play a role in the pathogenesis of the condition. Sterile pustules usually dry within several days, and desquamation and linear fissures are observed. ${ }^{7}$ In a case series, palms were exclusively affected in $15.4 \%$ of PPP cases, the soles in $17.9 \%$ and palms and soles were concomitantly altered in $66.7 \%$ of cases. ${ }^{7}$ The lesions usually cause an itching or burning sensation with a negative impact on the quality of life. ${ }^{10}$ In severe cases, particularly when cracking and fissuring happen, severe pain can be experienced, along with an inability to stand up, exercise, or manipulate objects, interfering with everyday activities. ${ }^{1}$

Nail changes may be present in about $42.1 \%$ of patients (a percentage lower than seen in psoriasis). ${ }^{7,48}$ In a retrospective review of Japanese patients, the most common alterations observed were onycholysis, pitting subungual, pustules and dystrophy. Other nail findings included sub-ungueal hyperkeratosis, scale, indention, longitudinal and transverse ridging, curvature abnormalities, splinter hemorrhage, discoloration and thickening of the nail. ${ }^{3}$ PPP patients can also have osteoarticular involvement in $25.6 \%{ }^{7,49}$

The differential diagnosis of PPP includes: irritant contact dermatitis, pityriasis rubra pilaris, dyshidrotic eczema, pompholyx, acrodermatitis continua of Hallopeau and fungal infections. ${ }^{50}$

\section{Histology}

Palmoplantar psoriasis is characterized histologically by orthokeratosis alternating with many foci of parakeratosis and the existence of inflammatory cells. ${ }^{4}$ The main microscopic finding of PPP is the sterile, unilocular intraepidermal pustules filled with eosinophils and neutrophils. Characteristics overlapping with psoriatic lesions can be found, such as parakeratosis, acanthosis, and inflammatory cell infiltration. ${ }^{3}$ In this disorder, it is verified that the epithelium degenerates, giving rise to a macro pustule eruption and in the upper layers of the dermis an inflammatory infiltrate with $\mathrm{CD} 3+\mathrm{T}$ lymphocytes and mast cells can be seen. ${ }^{4}$ It can be classified in vesicle, pustulovesicle and pustule phases. Pustules are not seen in all cases. Despite this, it is not possible to distinguish histopathologically between PPP and palmoplantar pustular psoriasis.

The primary differential diagnosis, histopathologically and clinically, is pompholyx. It has two phases: pustule and vesicle. ${ }^{51}$ Some studies have been written on histopathological differences between pompholyx and PPP. ${ }^{51}$ Kim et $\mathrm{al}^{52}$ and Yoon et $\mathrm{al}^{53}$ showed simple clues for the PPP and pompholyx differential diagnosis. MasudaKuroki et $\mathrm{al}^{51}$ recently described a new four-point checklist to distinguish PPP from pompholyx. Histopathological features favoring PPP are "vesicles lacking spongiosis" and "microabscesses on the edges of vesicles" and in favor of pompholyx are "vesicles with spongiosis" and "neutrophils only on the top, and no microabscesses on the edges of vesicles". ${ }^{1}$ On the other hand, when in the sequence of pompholyx pustules are present regularly, it is a big challenge for a pathomorphologist to distinguish between dyshidrotic eczema and palmoplantar pustulosis. ${ }^{53}$ Psoriasiform epidermal hyperplasia, confluent parakeratosis, loss of granular layer, extravasated erythrocytes, eosinophils in the pustules, tortuous and capillary capillaries that involve the surface of the epidermis suggest PPP. ${ }^{53}$ Intra-epidermal vesiculation and spongiosis are more characteristic of dyshidrotic eczema than PPP. ${ }^{53}$ In PPP lesions, the levels of IL- 8 and IL-17A are increased, while in eczema lesions, granzyme $\mathrm{B}$ is 
increased. This results fortified a separate immunological history and may be important for the diagnosis. ${ }^{52}$

Ericsson et $\mathrm{al}^{4}$ reported that in the skin of PPP, the inflammatory process affects the intraepidermal duct of the eccrine ducts or acrosyringium, leading to their elimination. Also, it has shown that in the affected skin, there is a reduction in the number of acrosyringeal ducts. ${ }^{4}$ Later, Murakami et al validated that the development of pustules begins in the acrosyringium. ${ }^{29}$

\section{Triggering Factors}

Smoking and upper respiratory infections have been suggested as main triggers of PPP. This association might be explained by an immune reaction to outside antigens that promotes autoreactivity features in individuals already genetically predisposed. ${ }^{27}$ Allergic contact dermatitis to nickel and topical therapeutic agents are frequently perceived as a trigger. ${ }^{54}$ Therefore, environmental, genetic, and immunological factors seem to have an important role in the development of the disease. ${ }^{3}$

\section{Smoking}

Smoking is the most recognized triggering factor in PPP. The prevalence of smoking is high in PPP patients, with percentages that range from $42-100 \%$ of active smokers or past smokers. ${ }^{7,11,12}$ The relative risk of developing PPP in current smokers is seventy-four times higher compared with non-smokers. ${ }^{12}$ Therefore, tobacco smoke is most reasonably implicated in the pathogenesis of the disease. ${ }^{55}$ Indeed, smoking induces oxidative stress and leads to an increase of inflammatory cells in the epidermis. Newly produced free radicals stimulate cellular signaling channels (as it also happens in psoriasis). Posteriorly, protein kinases are activated. Furthermore, nicotine stimulates macrophages and keratinocytes to liberate cytokines and activates $\mathrm{T}$ lymphocytes, leading to a chronic inflammatory process. ${ }^{11}$ There are also multiple case reports of lesion regression after smoke cessation. ${ }^{56}$

\section{Infections}

Infections, a well-recognized triggering factor in psoriasis vulgaris, can also exacerbate PPP ${ }^{57}$ Many case reports describe an association between PPP and tonsillitis, odontogenic infection (the most commonly reported) or chronic sinusitis. ${ }^{58}$ Indeed, clinical improvement in more than half of patients with PPP was observed by controlling dental disease. $^{58}$
The association between the tonsils and PPP was studied because tonsillectomy might be beneficial in patients with PPP (a study noted improvement in 109 of 116 patients with PPP). ${ }^{59}$ Several studies have shown that a hyperimmune response to $\alpha$-streptococci activates tonsillar $\mathrm{T}$ cells, which express several receptors, including cutaneous lymphocyte-associated antigen (CLA - a skinhoming receptor, responsible for the return to the skin), chemokine receptor 6 , and $\beta-1$ integrin. ${ }^{60}$ Interestingly, Nozawa et $\mathrm{al}^{60}$ showed that the number of tonsillar lymphocytes expressing CLA was increased in tonsillar mononuclear cells and tonsillar tissues in patients with PPP compared with in healthy controls. Activated tonsillar $\mathrm{T}$ cells migrate to PPP skin, releasing molecules like IL8 that lead to the aggregation of neutrophils in the skin lesions. It was observed that just a restricted set of $\mathrm{T}$ cell receptors is implicated in this mechanism, emphasizing the specificity of cross-reactivity to acrosiringium.

Pustular bacterid of Andrews consists of a clinical entity in which sterile pustules appear on the feet and hands after an upper respiratory tract infection, such as acute tonsillitis, in a skin spared from psoriasis lesions. ${ }^{61}$ Despite the controversy over Andrews' bacterial classification, this entity appears to have the same pathological and clinical pathway as palmoplantar pustulosis in terms of target and trigger. ${ }^{62}$ The main differentiating factor between Andrews' bacterid from palmoplantar psoriasis, cited in the literature, is the lack of psoriatic lesions. ${ }^{61}$ Andrews' bacterid may truly represent PPP. In view of this finding, some authors admit that PPP can be started by the return of specific autoreactive $T$ cells for bacteria to the skin and the development of an inflammatory cross reaction against uninfected tissues, leading to sterile pustulation. ${ }^{3}$ This theory was supported by the effectiveness of tonsillectomy in the treatment of palmoplantar pustulosis. Despite this, given the diminutive number of clinical reports, the force of the data to support the surgical procedure is yet lacking.

In addition to tonsillitis and dental infections, other infections can be considered as causing or worsening PPP. It has been presumed that $\mathrm{Ch}$. Trachomatis infections can possibly cause pustulosis. ${ }^{63}$ Anecdotal case reports also point out Helicobacter pylori as a potential cause of PPP. ${ }^{64}$

\section{Stress}

In certain dermatological disorders, including PPP, psychological factors, especially stress, can represent a significant role in their pathogenesis. Approximately $90 \%$ of patients 
with PPP describe exacerbations of the skin lesions in association with stress. Psychological tests have reinforced these clinical observations. A study using the Eysenck Personality Questionnaire (EPQ) showed that psychosomatic disorders, fear, and anxiety occur in $43 \%$ of patients with PPP, as opposed to $19 \%$ in the control group. ${ }^{65}$ When submitted to the Anxiety Situations and Responses Inventory (ISRA), autonomic nervous system activation (tachycardia, sweating and dry mouth) and fear were seen in $85 \%$ of patients with PPP, compared with $19 \%$ in the group with healthy people. ${ }^{65}$

\section{Allergy}

Based on observations from clinical practice, contact hypersensitivity seems to play an important role in PPP. Contact allergies are more common in patients with PPP, compared to people diagnosed with psoriasis vulgaris $(25.2 \%$ vs $11 \%)$. It has also been demonstrated that women with PPP have significantly more positive patch tests than men. ${ }^{66}$ A recent systematic review on contact allergy in PPP, showed that $23.3 \%$ of patients had positive patch tests and metals were the most common allergic agents. It also showed that in $58.3 \%$ of cases, dismissal of the allergens pointed to an improvement in skin, reinforcing the necessity for patch testing in patients with PPP. ${ }^{67}$ The most common allergens are nickel, Peru balsam, rubber additives, mercury and chromium. ${ }^{66}$ Consequently, performing patch tests in patients with PPP not responding to therapy can be helpful, and in some centers, they are made routinely during the diagnosis of PPP. Avoiding contact with the allergen is an essential part of treatment. ${ }^{66}$

\section{Drugs}

PPP is a disease that mainly affects adults and the elderly, meaning that many patients are polymedicated due to the coexistence of other chronic diseases. ${ }^{68}$ In a case-control study, $30 \%$ of patients were medicated with beta-blockers, angiotensin-converting enzyme (ACE) inhibitors or calcium channel blockers, $30 \%$ with hormone therapy, $15 \%$ antidepressants and $13 \%$ with antidiabetic drugs. ${ }^{69}$ Still, there is no clear association between these medications and PPP. A class of drugs that might be implicated in PPP are biologics. It was found that TNF inhibitors (adalimumab, infliximab and etanercept), despite being highly effective in treating psoriasis, can lead to the formation of psoriatic lesions as a side effect (psoriasis exacerbation or the development of inverse, pustular and erythrodermic forms. ${ }^{70}$ In fact, TNF inhibitors are the most common drugs to induce or exacerbate palmoplantar pustular lesions, and this can be the most common type of lesions provoked by these agents. ${ }^{70}$ Patients with inflammatory bowel disease treated with anti-TNF agents are at an increased risk of developing PPP, especially if they are male and young (10 to 39 years old). The mechanism that leads to the development of PPP is not completely understood. It has been proposed that the block of proinflammatory cytokines action, such as TNF, potentiates alternative pathways of $\mathrm{T}$ lymphocyte that result in the appearance of psoriatic lesions in predisposed individuals. ${ }^{68}$ Another biologic that may trigger PPP is rituximab, with some cases reported in the literature..$^{71,72}$

\section{Concomitant Diseases}

There are various disorders associated with a PPP, namely thyroid and parathyroid disease, metabolic syndrome, arthritis, coeliac disease and quality of life and psychiatric Disorders. PPP can also by one of the manifestations of SAPHO syndrome (Table 2.)

\section{Treatment}

PPP is a challenging disease to manage, and the treatment approach involves both topical and systemic therapies, as well as phototherapy and targeted molecules. Although many treatments have been tried and used over the years (most of them indicated for psoriasis, but with lower efficacy in PPP) no gold standard therapy has yet been identified, and no treatments are curative. ${ }^{70}$ The thicker stratum corneum present in the palms and soles represents an important barrier to proper local action of topical treatment agents, explaining the modest efficacy of these therapies. On the other hand, systemic treatments (retinoids, psoralen-ultraviolet A [PUVA], methotrexate, ciclosporin, and biologic therapy) have also shown limited efficacy when comparing with the results seen in chronic plaquetype psoriasis. Although classically topical corticosteroids under occlusion, acitretin, and PUVA have been described as effective in some studies, the improvement was reported as marginal and clinical relapse might occur. ${ }^{78}$ Also, the lack of randomized, controlled trials of conventional systemic and biologic therapies prevents accurate evaluation regarding their efficacy rates. These points should be kept in mind as the following treatment options are analyzed.

\section{Topical Treatment}

Topical therapy is considered the first-line for the management of PPP. ${ }^{78}$ In clinical practice, topically potent glucocorticosteroids, retinoids, vitamin D derivatives, 


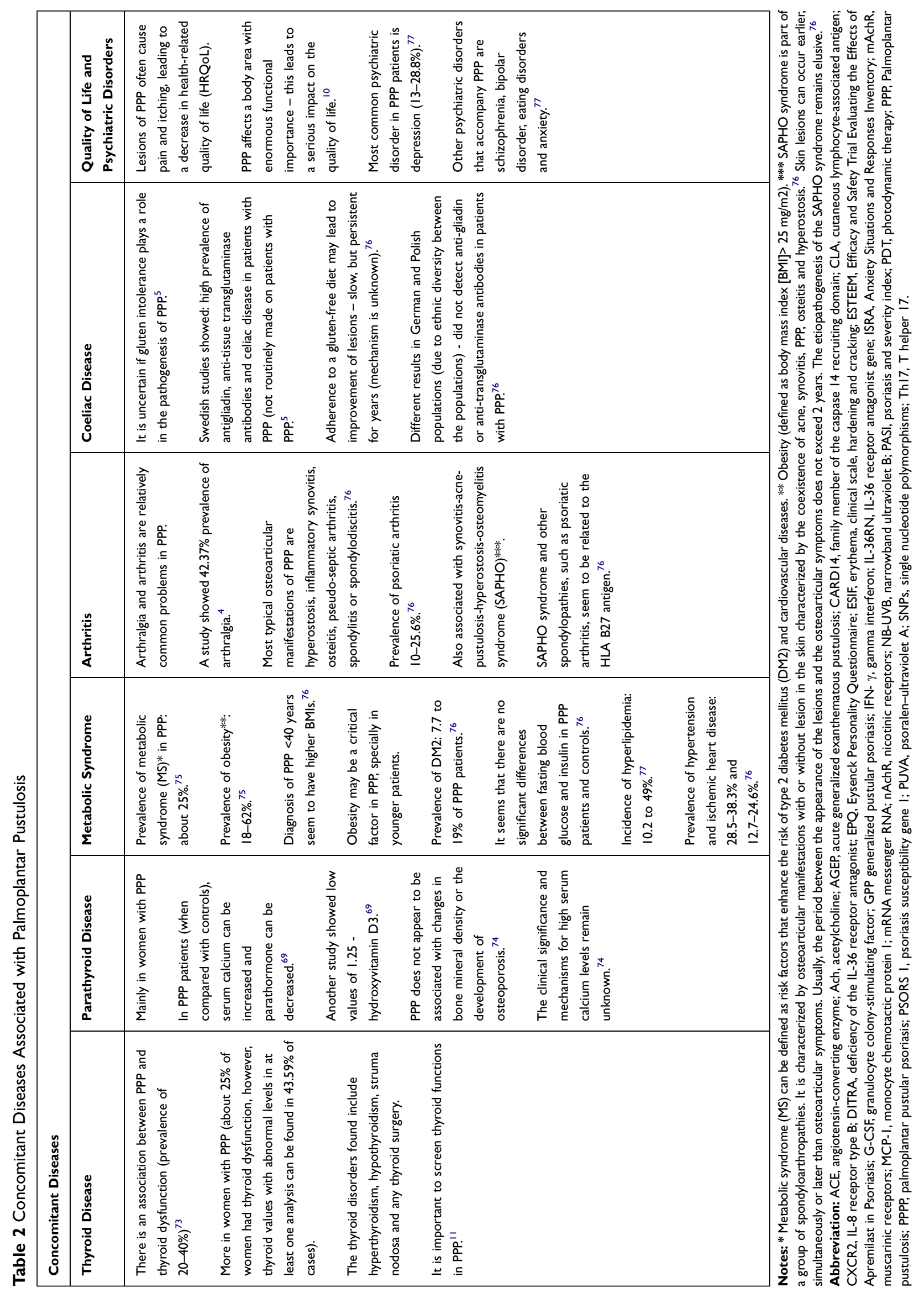


emollients, and keratolytic agents frequently are used, based principally on long clinical experience. The most frequently used topic treatments are topical corticosteroids, such as clobetasol propionate, acetonide triamcinolone cream, and betamethasone dipropionate, which should the applied under occlusion because it provides more effective penetration, might minimize the prolonged use, failure rate, and topical switching. ${ }^{78}$ Topical corticosteroids can cause numerous side effects, including tachyphylaxis, skin atrophy, and rebound effects. ${ }^{79}$ Retinoids (isotretinoin, tretinoin, retinol, alitretinoin, adapalene, retinaldehyde, and tazarotene) are also often used. The most common adverse effect is an irritation that is experienced during the beginning of treatment. Pregnancy is a contraindication. ${ }^{79}$

New drugs are in clinical trials for the efficient treatment of the disease, namely, a third-generation cephalosporin, the cefcapene pivoxil hydrochloride, and the maxacalcitol (22oxacalcitriol) ${ }^{80}$ Studies presented the topical maxacalcitol efficacy. A Cochrane systematic review found with lowquality evidence that maxacalcitol (topical vitamin D) might be more effective in clearing or almost clearing status than placebo and the risk of side effects (such as pruritus, mild local irritation, and urinary or haematological test abnormalities) is presumably comparable in both groups. ${ }^{79}$ It is contraindicated in hypercalcemia, pregnancy, lactation, and hepatic and renal failure. ${ }^{79}$

Beyond this, there is a case report that observed improvement in PPP lesions with a topical phosphodiesterase- 4 inhibitor, crisaborole and another case report that also showed improvements with the use $1 \%$ twice a day of tacrolimus ointment. ${ }^{80}$

As previously described, topical agents generally have only limited benefits in PPP, mainly due to low penetration into the thick stratum corneum of the soles and palms. ${ }^{81}$ Also, the use of several topics in resistant lesions can make the patient susceptible to contact hypersensitivity. ${ }^{82}$ Therefore, topic treatments should be the preferred approach in a patient with PPP. However, many patients end up, eventually requiring treatment with systemic drugs, which present risks of side effects that may restrict their use in clinical practice. ${ }^{83}$ Consequently, new topical treatments for PPP are needed for patients with concomitant illnesses and contraindications to systemic therapy.

\section{Phototherapy}

Phototherapy is a therapeutic option in PPP, and includes: ultraviolet A photochemotherapy (UVA) associated with topical or oral psoralen (PUVA - combination of psoralens and long-wave ultraviolet radiation), narrowband ultraviolet B (NB-UVB) phototherapy, excimer light therapy, and photodynamic therapy (PDT). They are usually welltolerated, with the most common side effects similar to intense sun exposure: transient superficial skin erythema, burn, and pain. NB-UVB is usually administered three to four times per week, while PUVA is usually administered three times per week. History of skin cancer is an absolute contraindication for both. ${ }^{84}$

In most studies, PUVA therapy is described and has been associated with moderate efficacy (complete or partial response in more than $40 \%$ of patients with PPP, although there is low quality of evidence. ${ }^{85}$ It seems to achieve an efficacy similar to that of classical oral treatments (acitretin, ciclosporin, methotrexate), and avoids the undesirable side effects of systemic therapies. The efficacy of PUVA may be increased in combination with oral retinoids, mainly acitretin. ${ }^{86}$ Nausea, ankle swelling, and non-purulent conjunctivitis are adverse events reported with oral PUVA. Blistering, erythema, and pruritus are the adverse effects associated with local PUVA.

NB-UVB phototherapy resulted in moderate to marked improvement in $73.3 \%$ of 16 patients with PPP and a $61.4 \%$ reduction in a modified PPPASI ${ }^{87}$ However, UVA phototherapy (both paint PUVA and UVA-1) appears to be superior to UVB phototherapy. ${ }^{88}$ A study showed $85.45 \%$ reduction in the severity index score with PUVA, compared with $61.03 \%$ with NB-UVB. In a pilot randomized controlled study with the two phototherapy options, $68.8 \%$ of patients showed marked improvement with UVA-1 phototherapy and only $34.4 \%$ during NB-UVB treatment. ${ }^{88}$

Another treatment option for patients with PPP is laser excimer NB-UVB, which has shown efficacy in $44.1-75 \%$ of cases. ${ }^{89}$ PDT appears to have limited efficacy in PPP.

As a conclusion, phototherapy is regarded as a wellestablished treatment with a good response rate, although frequent relapses are observed. Unfortunately, we still lack large comparative studies on the different phototherapy modalities, but based on the data so far as well as clinical experience, PUVA stands as the treatment method of choice in the majority of studies and reviews. PUVA is a safe and moderately effective therapeutic option, with the most common adverse event being mild erythema. ${ }^{86}$ The combination of PUVA and acitretin shows synergic effects, and the combination has been described in the 
literature as a valid therapeutic option with proven efficacy in patients with lesions that are resistant to phototherapy. ${ }^{86}$

\section{Systemic Treatment}

For the systemic treatment of PPP, several drugs are available with different outcomes, namely systemic retinoids (such as Acitretin and Alitretinoin), cyclosporine, methotrexate, tetracycline, hydroxyurea, colchicine, and itraconazole. $^{83}$

In PPP, the most widely used systemic treatment is acitretin. Acitretin is an effective treatment and may authors consider it as the primary systemic treatment, and, in a systematic review, Sevrain et $\mathrm{al}^{78}$ suggest that it should be the second-line in the treatment of palmoplantar pustulosis without psoriatic arthritis. In a study with acitretin, $93 \%$ of patients with PPP obtained a reduction in the mean number of pustules. ${ }^{83}$ The main adverse events identified with acitretin were due to mucocutaneous dryness (with dry mucosa of the mouth and nose and cheilitis) and a lipid imbalance. ${ }^{90}$ Acitretin has a teratogenic effect, so contraception is mandatory in women of childbearing potential. ${ }^{90}$ The approved dose ranges between 10 and $35 \mathrm{mg} /$ day. ${ }^{86}$ According to studies, the combination of acitretin with PUVA appears to produce a therapeutic benefit if an unsatisfactory response has been observed. ${ }^{91}$

The data regarding the use of alitretinoin in PPP are conflicting. Reich et $\mathrm{al}^{92}$ found that there were no significant differences in the outcomes between placebo and alitretinoin $30 \mathrm{mg}$ in the treatment of PPP. ${ }^{92}$ However, Brunasso et al ${ }^{93}$ stated that to evaluate the efficacy of this drug in PPP, more extensive studies are required. A systematic review by Cochrane states with moderate-quality evidence that oral alitretinoin is no more effective than a placebo in halving the severity of the disease and that there is no difference in adverse effects (eg, headache, cheilitis). Nonetheless, due to limited clinical experience with this drug, further clinical trials are needed to confirm its therapeutic role. ${ }^{79}$ Adverse effects of alitretinoin include dyslipidemia and mucocutaneous xerosis. Alitretinoin, like acitretin, is teratogenic and must be contraindicated in women of childbearing age. ${ }^{79}$

Methotrexate, tetracycline and cyclosporine may be useful for patients with PPP. ${ }^{79}$ Tetracycline is also contraindicated in pregnancy and children under the age of eight. Side effects are mainly abdominal pain, nausea, and genital candidiasis. ${ }^{79}$

Although methotrexate and cyclosporine cause only a modest response rate in patients with palmoplantar disease compared to that seen in chronic plaque psoriasis, these classic immunosuppressants achieved clinical improvement in patients with palmoplantar lesions (with $60.55 \%$ improvement with methotrexate in erythema, clinical scale, hardening and cracking [ESIF] and with cyclosporine a $50 \%$ reduction in the severity of the involved area was detected). ${ }^{83,84}$ The significant side effects of cyclosporine are hypertension and nephrotoxicity, while methotrexate can cause hepatic and hematological toxicities, limiting its long-term use. ${ }^{9}$ As retinoids, methotrexate provokes congenital malformations, and its application requires the use of contraception. ${ }^{9}$ Given the high-risk profile of these agents and the absence of additional benefit when compared to acitretin, it makes these two medications second-line agents for moderate to severe PPP that did not respond to acitretin/PUVA or in patients who have any contraindications acitretin/PUVA. ${ }^{9}$

\section{Targeted Therapies Approved for Psoriasis Vulgaris}

Biological agents have changed the therapeutic approach to severe and refractory cases of psoriasis. ${ }^{9}$ However, the high associated costs and possible adverse events related to immunomodulation/immunosuppression of these drugs have forced the necessity to apply criteria for their prescription. ${ }^{9}$ Most Phase 2 and 3 controlled and randomized studies for approval and verification of the safety of these molecules excluded patients with PPP. The exclusion occurs due to undefined criteria in the literature as well as these patients generally not achieving sufficiently high values in the area of psoriasis and severity index (PASI) and/or BSA to meet the criteria for inclusion of trials. Thus, data concerning the efficacy of biological agents in PPP are rare and are restricted to a low number of clinical reports and isolated clinical trials. It is important to emphasize that biological are symptomatic treatments, and as so, they do not affect the course of the disease.

\section{TNF Inhibitors}

Maybe due to differences in their inflammatory background, there are important differences in the clinical efficacy of antiTNF agents (adalimumab, etanercept, infliximab) in palmoplantar disease in contrast to chronic plaque psoriasis. Regarding PPP, the only placebo-controlled, prospective study, evaluating a TNF inhibitor was done with etanercept with only fifteen patients. It showed a significant decrease in median PPPASI score for patients treated with etanercept compared with placebo at week $24(\mathrm{p}=0.038)$, but no differences were noted at week 12 (the primary endpoint of 
the study). ${ }^{9}$ Interestingly, smoking may have been a key player in treatment efficacy, as the authors noted that three of three nonsmokers achieved clinical improvement with etanercept therapy while only three of seven active smokers improved. In a retrospective study, there were two cases of PPP treated with combination therapy of adalimumab and methotrexate or acitretin with good clinical response. ${ }^{76}$ Of note, there have been case reports of new-onset PPP or exacerbation of existing PPP during TNF-a inhibitor therapy for the treatment of other immune-mediated diseases. ${ }^{9}$ And this observation seems to be an anti-TNF class effect. The pathophysiologic mechanism for this paradoxical psoriasis is unknown, but an imbalance between TNF-a and IFN-a molecules in genetically predisposed individuals may be important. ${ }^{94}$ The conflicting results of efficacy with antiTNF agents led to the pursuit of molecules with a different mechanism of action. ${ }^{94}$

\section{IL-12/23 Inhibitors}

\section{Ustekinumab}

Ustekinumab, a drug that targets the p40 subunit common to IL-23 and IL-12, has exhibited conflicting results in PPP patients. It may be effective in some cases refractory to treatment with TNF-a inhibitors. ${ }^{76}$

Bissonnette et $\mathrm{al}^{33}$ carried out a prospective, randomized, and controlled study that did not show a statistically significant difference in efficacy using ustekinumab $45 \mathrm{mg}$ vs placebo in patients with PPP. Gerdes et $\mathrm{al}^{95}$ and Bertelsen et $\mathrm{al}^{96}$ also reported limited efficacy with the use of ustekinumab. However, Morales-Múnera et $\mathrm{al}^{97}$ found a positive response with with ustekinumab treatment. In another research, Au et a ${ }^{98}$ demonstrated higher efficacy with subcutaneous ustekinumab $90 \mathrm{mg}$ vs $45 \mathrm{mg}$. In fact, $67 \%$ of patients (six of nine subjects) who received a $90 \mathrm{mg}$ dose of ustekinumab achieved clinical clearance vs $9 \%$ (one of eleven) of subjects with a $45 \mathrm{mg}$ dose $(\mathrm{p}=0.02) .{ }^{98} \mathrm{In}$ another small group of four cases with recalcitrant PPP managed with ustekinumab, unsatisfactory outcomes were observed in two patients, complete resolution of the lesions in one patient, and partial resolution in another. ${ }^{9}$ The modest results seen may be explained by the low expression of IL-23 as opposed to IL-17 found in PPP. ${ }^{99}$

\section{IL-I7 Inhibitors}

Several studies have shown that IL-17 may play a central role in the inflammatory process of PPP. This means that biologic agents acting on IL-17 may represent a more effective therapeutic option than anti-TNF and anti- IL-
$12 / 23$ agents for this group of patients. ${ }^{33}$ Since there is analogous expression of IL-17 in palmoplantar pustulosis lesions a positive response to anti-IL-17 biologics in these patients is very likely. Among the IL-17 inhibitors, secukinumab and brodalumab have been specifically studies in PPP patients. ${ }^{76}$ In a multicenter, randomized, double-blind clinical trial (2PRECISE) that involved over 200 patients with PPP, secukinumab $300 \mathrm{mg}$ and $150 \mathrm{mg}$ were compared with placebo. At week 52, $41.8 \%$ of the patients that received secukinumab $300 \mathrm{mg}$ reached PPPASI-75, and $43.1 \%$ had a DLQI response of 0 or $1 .{ }^{76}$ A recent systematic review concluded there was moderate-quality evidence that secukinumab is probably more effective than placebo in achieving 50\% reduction in disease severity. ${ }^{79} \mathrm{~A}$ case series of four patients receiving brodalumab reported a lack of efficacy or moderate improvement in the treatment of PPP. ${ }^{76}$ A Phase III placebo-controlled study on the efficacy of brodalumab in subjects with PPP is ongoing. ${ }^{76}$

\section{IL-23 Inhibitors}

\section{Guselkumab}

Guselkumab, a fully human monoclonal antibody that binds to the p19 subunit of IL-23, has been studied in PPP patients. ${ }^{100,101}$ Terui et al ${ }^{101}$ announced the outcomes of a double-blind, randomized, placebo-controlled clinical trial with 49 PPP patients treated with guselkumab showing clinical efficacy at week 16 , however, the clinical response started only at week 2 . A multicenter, Phase III, randomized, double-blind, placebo-controlled study on the safety and efficacy of guselkumab in 159 subjects with PPP was recently published, showing that using guselkumab $100 \mathrm{mg}$ and $200 \mathrm{mg}$ led to significant improvement in the PPPASI score at week 16, yet, it was only with guselkumab $100 \mathrm{mg}$ that it was statistically significant ( $\mathrm{p}$ $<0.001)^{76}$ Additional reductions in PPSI and PPPASI scores were observed in the 100 and $200 \mathrm{mg}$ groups up to week 52. The PPPASI-75 response was obtained in $55.6 \%$ of cases taking guselkumab $100 \mathrm{mg}$ and in 59.6\% in those used guselkumab $200 \mathrm{mg}$ at week $52 .{ }^{76}$ Blauvelt et $\mathrm{al}^{102}$ in a clinical trial, noted a significant clinical clearance in sufferers treated with the drug compared to placebo at 16 weeks $(85.1 \%$ with an AGI of 0 or 1 ; $\mathrm{p}<0.001$ ) and observed that $90 \%$ of all patients improved by receiving treatment with guselkumab. However, there is no certainty about the effect that guselkumab has on the clearance of lesions, as the evidence is of very low quality, but it is thought that guselkumab may increase the likelihood of achieving a $50 \%$ reduction in disease severity 
compared to placebo (evidence with moderate quality). We would like to underline that guselkumab is the only biologic to date to be approved specifically for the treatment of PPP patients (in Japan).

\section{Phosphodiesterase-4 (PDE-4) Inhibitor}

Apremilast, the first oral alternative to biologic therapies in psoriasis, is a selective PDE-4 inhibitor. ${ }^{103}$ The inhibition of PDE-4 blocks production of several inflammatory cytokines that are central in psoriasis pathogenesis, such as IFN-c, TNFa, IL-12, IL- 17, and IL-23. ${ }^{104}$ Although it demonstrated only moderate clinical efficacy in patients with plaque psoriasis in the Phase 3 ESTEEM [Efficacy and Safety Trial Evaluating the Effects of Apremilast in Psoriasis] and 2 trials, it showed efficacy in difficult-to-treat psoriatic subtypes such as nail psoriasis, scalp psoriasis, and palmoplantar psoriasis. ${ }^{9,104}$ Its action in a wide spectrum of cytokines, supported by efficacy demonstrated in palmoplantar psoriasis, raised the possibility of apremilast also being a possible therapeutic option is PPP. As an added benefit, it also presents a favorable safety profile (mild adverse events and no laboratory test monitoring needed). ${ }^{9,104}$ The data so far seem to support its use in PPP patients. $^{76}$ Two retrospective studies (with a total of 12 subjects) used apremilast in combination with ustekinumab, methotrexate, or ixekizumab with good clinical response. ${ }^{76}$ Four more cases of PPP effectively treated with apremilast in monotherapy have also been published. ${ }^{76}$ Prospective data is needed to confirm these observations.

\section{Emerging Agents \\ IL-8 Inhibitors}

The efficacy of HuMab10F8, an anti-IL-8 monoclonal antibody, in PPP was reported in 2008 in an open-label multicenter study with a single-dose dose-escalation setup. ${ }^{105} 37 \%$ of subjects at week 4 and $61 \%$ of subjects at week 8 had a decrease of $\geq 50 \%$ in number of new pustules. Regarding dose, all seven patients in the highdose group achieved at least a $50 \%$ reduction in number of new pustules, with four patients having a $75 \%$ reduction from baseline to week $8{ }^{105}$ Until now, the drug is not approved in any indication, and no further reports of the use of this agent in PPP have been published. However, a randomized, double-blind, placebo-controlled, phase IIa study is currently studying RIST4721 (also known as AZD4721), an orally administered molecule, that exerts an anti-inflammatory effect by blocking CXCR2 (IL-8B receptor) on the surface of inflammatory cells. ${ }^{76}$

\section{IL-36 Inhibitors}

Recent PPP trials are focusing on blockage of IL-36, which play an important role in innate immunity. Three studies are currently evaluating the use of monoclonal antibodies that block the IL-36 receptor in PPP: ANB019 and spesolimab (BI 655130). Spesolimab is also being investigated in generalized pustular psoriasis, ulcerative colitis, Crohn disease, and atopic dermatitis. A Phase I, open-label, proof-of-concept study, enrolled seven patients with a generalized pustular psoriasis flare. Participants were treated with a single intravenous dose of spesolimab (10 mg per kilogram of body weight). ${ }^{106}$ Spesolimab was effective in all seven patients after a single intravenous dose (all patients achieved a Generalized Pustular Psoriasis Physician Global Assessment score of 0 or 1 by week 4 , and the score was sustained up to week 20 ). ${ }^{76}$ Of note, only three of the seven patients had a homozygous IL36RN mutation, and one also had the CARD14 mutation (has been associated with pustular skin disease), indicating that spesolimab was effective in generalized pustular psoriasis regardless of the presence of IL36RN mutations. For PPP patients, this is a key finding, as genetic studies have shown that IL36RN mutations are found in only in a low percentage. ${ }^{76}$ No serious adverse events were reported.

\section{IL-I Inhibitors}

There are two active studies of anakinra in PPP. ${ }^{107}$ Anakinra is an IL-1 receptor antagonist that is currently registered for rheumatic arthritis, Still's disease, and cryopyrin associated periodic syndromes. Clinical trials are ongoing in many other pathologies, including inflammatory pustular diseases and hidradenitis suppurativa. In a report of two cases of severe PPPP treated with subcutaneous anakinra $100 \mathrm{mg}$, there was only a partial clinical response and the treatment was stopped after 3 and 2 months due to lack of efficacy or side effects, respectively. ${ }^{76}$

\section{Granulocyte Colony Stimulating Factor Receptor Inhibitor}

CSL324 is a recombinant anti-granulocyte colonystimulating factor (G-CSF) receptor monoclonal antibody. A phase I, multicenter, open-label study is currently ongoing for CSL324 in PPP and hidradenitis suppurativa. ${ }^{76}$

\section{Conclusion}

PPP is a chronic and debilitating skin condition that has a negative impact on the quality of life. It has genetic, histopathologic and clinical features that are not present in psoriasis. As an example, the psoriasis susceptibility gene 
locus (PSORS1) is strongly associated with psoriasis but is not found in patients with PPP. Also, both a missense mutation in the interleukin (IL)-36 receptor antagonist (IL36RN) and caspase recruitment domain family member 14 (CARD14), which may influence response to treatment have been identified in patients with PPP. ${ }^{15}$ However, both psoriasis and PPP involve IL-17 as a mediator of inflammation, in addition to interferon-gamma and TNF-a. ${ }^{13}$

Although many therapeutic approaches have been tried for this condition, there is an absence of a gold standard. ${ }^{79}$ Clinical evaluation is key in patients with PPP to tailor the treatment according to the patient's personal and disease context. In active smokers with resistant disease, smoking cessation counseling may be recommended, once it diminishes the inflammatory stimulus and allows for a better treatment response. ${ }^{9}$ In patients with mild disease, control may be achieved with on-demand occlusion of topical agents (an easy, accessible, systemic adverse eventfree treatment option). In patients with moderate-to-severe PPP, phototherapy or a classical systemic agent (acitretin being the best treatment option, especially in combination with PUVA), may be effective. Refractory patients or those with contraindications to use of these therapies may be good candidates for newer therapies. Guselkumab is the only biologic approved for PPP (in Japan), Some date suggest the benefit of other IL-17 agents and apremilast. Implementation of early effective treatment, considering the disease severity and quality-of-life impact, results in a lesser economic burden than use of excessive, ineffective, and expensive treatment regimens. An effective treatment is not equal to complete clearance, since complete clearance may not be necessary if patients achieve sufficient improvement to perform activities of daily living and occupational tasks without pain or discomfort. ${ }^{10}$

Further clinical trials are needed to assess efficacy and tolerance of therapies for this debilitating and therapeutically challenging condition. Luckily the future seems brighter, with studies in PPP, currently focusing on the genetic aspects and the role of IL-17 and IL-36 pathways and microbiomes in the etiopathogenesis. Clinical trials are evaluating or have evaluated targeted therapies in PPP for more than 12 molecules, including CXCR2 (IL-8 receptor type B), G-CSF receptor, IL-1 receptor, IL-8, IL-12, IL-23, IL-17A, IL-17 receptor, IL-36 receptor, PDE-4, and TNFa.

\section{Disclosure}

Egidio Freitas and Maria Alexandra Rodrigues have no conflicts of interest to declare.
Tiago Torres has received research grants and/or consulting fees from AbbVie, Almirall, Amgen, Arena Pharmaceuticals, Biocad, Boehringer Ingelheim, Bristol-Myers Squibb, Celgene, Eli Lilly, Janssen, LEO Pharma, MSD, Novartis, Pfizer, Samsung-Bioepis, Sandoz, Sanofi.

\section{References}

1. Wolff K, Goldsmith L, Katz S, Gilchrest B, Paller A, Leffell D. Fitzpatrick's Dermatology in General Medicine. 7th ed. McGrawHill Professional; 2008.

2. Kumar B, Saraswat A, Kaur I. Palmoplantar lesions in psoriasis: a study of 3065 patients. Acta Derm Venereol. 2002;82 (3):192-195. doi:10.1080/00015550260132488

3. Yamamoto T. Extra-palmoplantar lesions associated with palmoplantar pustulosis. J Eur Acad Dermatology Venereol. 2009;23 (11):1227-1232. doi:10.1111/j.1468-3083.2009.03296.x

4. Eriksson H, Lundin M. Palmoplantar pustulosis: a clinical and immunohistological study. Br J Dermatol. 1998;138(3):390-398. doi:10.1046/j.1365-2133.1998.02113.x

5. Michaëlsson G, Kristjánsson G, Pihl Lundin I, Hagforsen E. Palmoplantar pustulosis and gluten sensitivity: a study of serum antibodies against gliadin and tissue transglutaminase, the duodenal mucosa and effects of gluten-free diet. $\mathrm{Br}$ $J$ Dermatol. 2007;156(4):659-666. doi:10.1111/j.13652133.2006.07725.x

6. Kubota K, Kamijima Y, Sato T, et al. Epidemiology of psoriasis and palmoplantar pustulosis: a nationwide study using the Japanese national claims database. BMJ Open. 2015;5(1): e006450-e006450. doi:10.1136/bmjopen-2014-006450

7. Brunasso AMG, Puntoni M, Aberer W, Delfino C, Fancelli L, Massone C. Clinical and epidemiological comparison of patients affected by palmoplantar plaque psoriasis and palmoplantar pustulosis: a case series study. $B r \quad J$ Dermatol. 2013;168 (6):1243-1251. doi:10.1111/bjd.12223

8. Navarini AA, Burden AD, Capon F, et al. European consensus statement on phenotypes of pustular psoriasis. J Eur Acad Dermatology Venereol. 2017;31(11):1792-1799. doi:10.1111/jdv.14386

9. Raposo I, Torres T. Palmoplantar psoriasis and palmoplantar pustulosis: current treatment and future prospects. Am J Clin Dermatol. 2016;17(4):349-358. doi:10.1007/s40257-016-01917

10. Pettey A, Balkrishnan R, Rapp SR, Fleischer AB, Feldman SR. Patients with palmoplantar psoriasis have more physical disability and discomfort than patients with other forms of psoriasis: implications for clinical practice. J Am Acad Dermatol. 2003;49 (2):271-275. doi:10.1067/S0190-9622(03)01479-8

11. Gimenez-Garcia R, Sanchez-Ramon S, Cuellar-Olmedo L. Palmoplantar pustulosis: a clinicoepidemiological study. The relationship between tobacco use and thyroid function. J Eur Acad Dermatology Venereol. 2003;17(3):276-279. doi:10.1046/j.14683083.2003.00510.x

12. Hagforsen E, Mustafa A, Lefvert A-K, Nordlind K, Michaëlsson G. Palmoplantar pustulosis: an autoimmune disease precipitated by smoking? Acta Derm Venereol. 2002;82 (5):341-346. doi:10.1080/000155502320624069

13. Asumalahti K, Ameen M, Suomela S, et al. Genetic analysis of PSORS1 distinguishes guttate psoriasis and palmoplantar pustulosis. $J$ Invest Dermatol. 2003;120(4):627-632. doi:10.1046/j.1523-1747.2003.12094.x

14. Ding L, Wang X, Hong X, Lu L, Liu D. IL-36 cytokines in autoimmunity and inflammatory disease. Oncotarget. 2018;9 (2):2895-2901. doi:10.18632/oncotarget.22814 
15. Prieto-Pérez R, Cabaleiro T, Daudén E, Ochoa D, Roman M, AbadSantos F. Genetics of psoriasis and pharmacogenetics of biological drugs. Autoimmune Dis. 2013;2013:1-13. doi:10.1155/2013/613086

16. Marrakchi S, Guigue P, Renshaw BR, et al. Interleukin-36-receptor antagonist deficiency and generalized pustular psoriasis. $N$ Engl J Med. 2011;365(7):620-628. doi:10.1056/NEJMoa1013068

17. Twelves S, Mostafa A, Dand N, et al. Clinical and genetic differences between pustular psoriasis subtypes. J Allergy Clin Immunol. 2019;143(3):1021-1026. doi:10.1016/j.jaci.2018.06.038

18. Mössner R, Frambach Y, Wilsmann-Theis D, et al. Palmoplantar pustular psoriasis is associated with missense variants in CARD14, but not with loss-of-function mutations in IL36RN in european patients. $J$ Invest Dermatol. 2015;135(10):2538-2541. doi:10.1038/jid.2015.186

19. Wang T-S, Chiu H-Y, Hong J-B, Chan -C-C, Lin S-J, Tsai T-F. Correlation of IL36RN mutation with different clinical features of pustular psoriasis in Chinese patients. Arch Dermatol Res. 2016;308(1):55-63. doi:10.1007/s00403-015-1611-x

20. Johnston A, Xing X, Wolterink L, et al. IL-1 and IL-36 are dominant cytokines in generalized pustular psoriasis. J Allergy Clin Immunol. 2017;140(1):109-120. doi:10.1016/j.jaci.2016.08.056

21. Nakai N, Sugiura K, Akiyama M, Katoh N. Acute generalized exanthematous pustulosis caused by dihydrocodeine phosphate in a patient with psoriasis vulgaris and a heterozygous IL36RN mutation. JAMA Dermatol. 2015;151(3):311. doi:10.1001/ jamadermatol.2014.3002

22. Mössner R, Wilsmann-Theis D, Oji V, et al. The genetic basis for most patients with pustular skin disease remains elusive. $\mathrm{Br}$ J Dermatol. 2018;178(3):740-748. doi:10.1111/bjd.15867

23. Mössner R, Kingo K, Kleensang A, et al. Association of TNF -238 and -308 promoter polymorphisms with psoriasis vulgaris and psoriatic arthritis but not with pustulosis palmoplantaris. $J$ Invest Dermatol. 2005;124(1):282-284. doi:10.1111/j.0022202X.2004.23556.X

24. Kingo K, Mössner R, Kõks S, et al. Association analysis of IL19, IL20 and IL24 genes in palmoplantar pustulosis. Br J Dermatol. 2007;156(4):646-652. doi:10.1111/j.1365-2133.2006.07731.x

25. Douroudis K, Kingo K, Traks T, et al. ATG16L1 gene polymorphisms are associated with palmoplantar pustulosis. Hum Immunol. 2011;72(7):613-615. doi:10.1016/j.humimm.2011.03.009

26. Szanto E, Linse U. Arthropathy associated with palmoplantar pustulosis. Clin Rheumatol. 1991;10(2):130-135. doi:10.1007/ BF02207650

27. Hagforsen E, Hedstrand H, Nyberg F, Michaëlsson G. Novel findings of Langerhans cells and interleukin-17 expression in relation to the acrosyringium and pustule in palmoplantar pustulosis. Br J Dermatol. 2010;163(3):572-579. doi:10.1111/ j.1365-2133.2010.09819.x

28. Yoon SY, Park HS, Yoon HS, Chung JH, Cho S. Utility of epithelial membrane antigen immunostaining in the differentiation between palmoplantar pustulosis and pompholyx. J Eur Acad Dermatology Venereol. 2013;27(8):1054-1056. doi:10.1111/ j.1468-3083.2012.04702.x

29. Murakami M, Ohtake T, Horibe Y, et al. Acrosyringium is the main site of the vesicle/pustule formation in palmoplantar pustulosis. J Invest Dermatol. 2010;130(8):2010-2016. doi:10.1038/jid.2010.87

30. Hagforsen E, Edvinsson M, Nordlind K, Michaelsson G. Expression of nicotinic receptors in the skin of patients with palmoplantar pustulosis. Br J Dermatol. 2002;146(3):383-391. doi:10.1046/j.1365-2133.2002.04640.x

31. Hagforsen E, Michaëlsson G, Stridsberg M. Normal and PPP-affected palmoplantar sweat gland express neuroendocrine markers chromogranins and synaptophysin differently. Arch Dermatol Res. 2010;302(9):685-693. doi:10.1007/s00403-0101070-3
32. Murakami M, Hagforsen E, Morhenn V, Ishida-Yamamoto A, Iizuka H. Patients with palmoplantar pustulosis have increased IL-17 and IL-22 levels both in the lesion and serum. Exp Dermatol. 2011;20(10):845-847. doi:10.1111/j.16000625.2011.01325.x

33. Bissonnette R, Nigen S, Langley RG, et al. Increased expression of IL-17A and limited involvement of IL-23 in patients with palmo-plantar (PP) pustular psoriasis or PP pustulosis; results from a randomised controlled trial. J Eur Acad Dermatology Venereol. 2014;28(10):1298-1305. doi:10.1111/jdv.12272

34. Lee E, Zarei M, LaSenna C, Villada G, Romanelli P. Psoriasis targeted therapy: characterization of interleukin $17 \mathrm{~A}$ expression in subtypes of psoriasis. $J$ Drugs Dermatol. 2015;14 (10):1133-1136.

35. Croxford AL, Karbach S, Kurschus FC, et al. IL-6 Regulates neutrophil microabscess formation in IL-17A-driven psoriasiform lesions. J Invest Dermatol. 2014;134(3):728-735. doi:10.1038/ jid.2013.404

36. Rincon M. Interleukin-6: from an inflammatory marker to a target for inflammatory diseases. Trends Immunol. 2012;33 (11):571-577. doi:10.1016/j.it.2012.07.003

37. Bartoccioni E, Scuderi F, Marino M, Provenzano C. IL-6, monocyte infiltration and parenchymal cells. Trends Immunol. 2003;24 (6):298-299. doi:10.1016/S1471-4906(03)00112-1

38. Jones SA, Scheller J, Rose-John S. Therapeutic strategies for the clinical blockade of IL-6/gp130 signaling. J Clin Invest. 2011;121 (9):3375-3383. doi:10.1172/JCI57158

39. Tortola L, Rosenwald E, Abel B, et al. Psoriasiform dermatitis is driven by IL-36-mediated DC-keratinocyte crosstalk. J Clin Invest. 2012;122(11):3965-3976. doi:10.1172/JCI63451

40. Carrier Y, Ma H-L, Ramon HE, et al. Inter-regulation of Th17 cytokines and the IL-36 cytokines in vitro and in vivo: implications in psoriasis pathogenesis. J Invest Dermatol. 2011;131 (12):2428-2437. doi:10.1038/jid.2011.234

41. Mahil SK, Catapano M, Di Meglio P, et al. An analysis of IL-36 signature genes and individuals with IL1RL2 knockout mutations validates IL-36 as a psoriasis therapeutic target. Sci Transl Med. 2017;9(411):eaan2514. doi:10.1126/scitranslmed. aan2514

42. Sugiura K, Takemoto A, Yamaguchi M, et al. The majority of generalized pustular psoriasis without psoriasis vulgaris is caused by deficiency of interleukin-36 receptor antagonist. $J$ Invest Dermatol. 2013;133(11):2514-2521. doi:10.1038/jid.2013.230

43. Murakami M, Kaneko T, Nakatsuji T, et al. Vesicular LL-37 contributes to inflammation of the lesional skin of palmoplantar pustulosis. Proost P, ed. PLoS One. 2014;9(10):e110677. doi:10.1371/journal.pone.0110677

44. Xiaoling Y, Chao W, Wenming W, Feng L, Hongzhong J. Interleukin (IL)-8 and IL-36 $\gamma$ but not IL-36Ra are related to acrosyringia in pustule formation associated with palmoplantar pustulosis. Clin Exp Dermatol. 2019;44(1):52-57. doi:10.1111/ ced.13689

45. Jiang WG, Sanders AJ, Ruge F, Harding KG. Influence of interleukin-8 (IL-8) and IL-8 receptors on the migration of human keratinocytes, the role of PLC- $\gamma$ and potential clinical implications. Exp Ther Med. 2012;3(2):231-236. doi:10.3892/ etm.2011.402

46. Wolk K, Frambach Y, Jacobi A, et al. Increased levels of lipocalin 2 in palmoplantar pustular psoriasis. J Dermatol Sci. 2018;90 (1):68-74. doi:10.1016/j.jdermsci.2017.12.018

47. Masuda-Kuroki K, Murakami M, Tokunaga N, et al. The microbiome of the "sterile" pustules in palmoplantar pustulosis. Exp Dermatol. 2018;27(12):1372-1377. doi:10.1111/exd.13791

48. Burden AD, Kemmett D. The spectrum of nail involvement in palmoplantar pustulosis. Br J Dermatol. 1996;134(6):1079-1082. doi:10.1046/j.1365-2133.1996.d01-905.x 
49. Yamamoto T. Pustulotic arthro-osteitis associated with palmoplantar pustulosis. J Dermatol. 2013;40(11):857-863. doi:10.11 11/1346-8138.12272

50. Coenraads P-J. Hand Eczema. $N$ Engl J Med. 2012;367 (19):1829-1837. doi:10.1056/NEJMcp1104084

51. Masuda-Kuroki K, Murakami M, Kishibe M, et al. Diagnostic histopathological features distinguishing palmoplantar pustulosis from pompholyx. J Dermatol. 2019;46(5):399-408. doi:10.1111/ 1346-8138.14850

52. Kim DY, Kim JY, Kim TG, et al. A comparison of inflammatory mediator expression between palmoplantar pustulosis and pompholyx. J Eur Acad Dermatology Venereol. 2013;27 (12):1559-1565. doi:10.1111/jdv.12203

53. Yoon SY, Park HS, Lee JH, Cho S. Histological differentiation between palmoplantar pustulosis and pompholyx. J Eur Acad Dermatology Venereol. 2013;27(7):889-893. doi:10.1111/j.14683083.2012.04602.x

54. Hill VA, Ostlere LS. Psoriasis of the hands köbnerizing in contact dermatitis. Contact Dermatitis. 1998;39(4):194. doi:10.1111/ j.1600-0536.1998.tb05894.x

55. Akiyama T, Seishima M, Watanabe H, Nakatani A, Mori S, Kitajima Y. The relationships of onset and exacerbation of pustulosis palmaris et plantaris to smoking and focal infections. $J$ Dermatol. 1995;22(12):930-934. doi:10.1111/j.1346-8138. 1995.tb03948.x

56. de Waal AC. van de Kerkhof PCM. Pustulosis palmoplantaris is a disease distinct from psoriasis. J Dermatolog Treat. 2011;22 (2):102-105. doi:10.3109/09546631003636817

57. Kobayashi S. Tonsil-related skin diseases and possible involvement of $\mathrm{T}$ cell co-stimulation in chronic focal infection. In: 2011;83-85. doi:10.1159/000324614

58. Kouno M, Nishiyama A, Minabe M, et al. Retrospective analysis of the clinical response of palmoplantar pustulosis after dental infection control and dental metal removal. J Dermatol. 2017;44 (6):695-698. doi:10.1111/1346-8138.13751

59. Takahara M, Hirata Y, Nagato T, et al. Treatment outcome and prognostic factors of tonsillectomy for palmoplantar pustulosis and pustulotic arthro-osteitis: a retrospective subjective and objective quantitative analysis of 138 patients. $J$ Dermatol. 2018;45(7):812-823. doi:10.1111/1346-8138.14348

60. Nozawa H, Kishibe K, Takahara M, Harabuchi Y. Expression of cutaneous lymphocyte-associated antigen (CLA) in tonsillar T-cells and its induction by in vitro stimulation with alpha-streptococci in patients with pustulosis palmaris et plantaris (PPP). Clin Immunol. 2005;116(1):42-53. doi:10.1016/j. clim.2005.01.009

61. Bacharach-Buhles M, El Gammal AP. The pustular bacterid (Andrews). Are there clinical criteria for differentiating from psoriasis pustulosa palmaris et plantaris? Der Hautarzt; Zeitschrift fur Dermatologie, Venerol und Verwandte Gebiete. 1993;44:221-224.

62. Abtahi-Naeini B, Heydari H, Pourazizi M, Iraji F. Pustular bacterid: look at the throat for prevention over treatment. Int J Prev Med. 2015;6(1):51. doi:10.4103/2008-7802.158180

63. Quint K, van der Helm-van Mil AH, Bergman W, Lavrijsen K. Mucocutaneous abnormalities in Chlamydia trachomatis-induced reactive arthritis. Ned Tijdschr Geneeskd. 2010;154:A1614.

64. Hübner AM, Tenbaum SP. Complete remission of palmoplantar psoriasis through Helicobacter pylori eradication: a case report. Clin Exp Dermatol. 2008;33(3):339-340. doi:10.1111/j.13652230.2007.02634.x

65. Saez-Rodriguez M, Noda-Cabrera A, Alvarez-Tejera S, et al. The role of psychological factors in palmoplantar pustulosis. $J$ Eur Acad Dermatology Venereol. 2002;16(4):325-327. doi:10.1046/ j.1468-3083.2002.00538.x
66. Ito T, Mori T, Fujiyama T, Tokura Y. Dramatic exacerbation of palmoplantar pustulosis following strongly positive nickel patch testing. Int J Dermatol. 2014;53(5):e327-e329. doi:10.1111/ ijd. 12242

67. Brunasso Vernetti AMG, Puntoni M, Massone C. Palmoplantar pustulosis and allergies: a systematic review. Dermatol Pract Concept. 2019;105-110. doi:10.5826/dpc.0902a05

68. Bordel-Gómez M, Sánchez-Estella J, Martínez-González O, Cardeñoso-Álvarez M. Palmoplantar psoriasis: a paradoxical adverse reaction induced by adalimumab. $J$ Eur Acad Dermatology Venereol. 2009;23(4):444-445. doi:10.1111/j.14683083.2008.02898.x

69. Hagforsen E, Michaëlsson K, Lundgren E, et al. Women with palmoplantar pustulosis have disturbed calcium homeostasis and a high prevalence of diabetes mellitus and psychiatric disorders: a case-control study. Acta Derm Venereol. 2005;1(1):1. doi:10.1080/00015550510026587

70. Shmidt E, Wetter DA, Ferguson SB, Pittelkow MR. Psoriasis and palmoplantar pustulosis associated with tumor necrosis factor- $\alpha$ inhibitors: the Mayo Clinic experience, 1998 to 2010. J Am Acad Dermatol. 2012;67(5):e179-e185. doi:10.1016/j.jaad.2011.05.038

71. Brunasso AMG, Massone C. Plantar pustulosis during rituximab therapy for rheumatoid arthritis. J Am Acad Dermatol. 2012;67 (4):e148-e150. doi:10.1016/j.jaad.2011.12.010

72. Venables ZC, Swart SS, Soon CS. Palmoplantar pustulosis secondary to rituximab: a case report and literature review. Clin Exp Dermatol. 2015;40(4):451-452. doi:10.1111/ced.12527

73. Brunasso A, Massone C. Can we really separate palmoplantar pustulosis from psoriasis? J Eur Acad Dermatology Venereol. 2010;24(5):619-621. doi:10.1111/j.1468-3083.2010.03648.x

74. Hagforsen E, Pihl-Lundin I, Michaëlsson K, Michaëlsson G. Calcium homeostasis and body composition in patients with palmoplantar pustulosis: a case-control study. $\mathrm{Br} J$ Dermatol. 2012;166(1):74-81. doi:10.1111/j.1365-2133.2011.10622.x

75. Trattner H, Blüml S, Steiner I, Plut U, Radakovic S, Tanew A. Quality of life and comorbidities in palmoplantar pustulosis - a cross-sectional study on 102 patients. J Eur Acad Dermatology Venereol. 2017;31(10):1681-1685. doi:10.1111/jdv.14187

76. Misiak-Galazka M, Zozula J, Rudnicka L. Palmoplantar pustulosis: recent advances in etiopathogenesis and emerging treatments. Am J Clin Dermatol. 2020. doi:10.1007/s40257-020-00503-5

77. Becher G, Jamieson L, Leman J. Palmoplantar pustulosis a retrospective review of comorbid conditions. J Eur Acad Dermatology Venereol. 2015;29(9):1854-1856. doi:10.1111/ jdv. 12545

78. Sevrain M, Richard M-A, Barnetche T, et al. Treatment for palmoplantar pustular psoriasis: systematic literature review, evidence-based recommendations and expert opinion. J Eur Acad Dermatology Venereol. 2014;28:13-16. doi:10.1111/jdv.12561

79. Obeid G, Do G, Kirby L, Hughes C, Sbidian E, Le Cleach L. Interventions for chronic palmoplantar pustulosis. Cochrane Database Syst Rev. 2020. doi:10.1002/14651858.CD011628.pub2

80. Umezawa Y, Nakagawa H, Tamaki K. Phase III clinical study of maxacalcitol ointment in patients with palmoplantar pustulosis: a randomized, double-blind, placebo-controlled trial. J Dermatol. 2016;43(3):288-293. doi:10.1111/1346-8138.13064

81. Bissonnette R, Poulin Y, Guenther L, Lynde CW, Bolduc C, Nigen S. Treatment of palmoplantar psoriasis with infliximab: a randomized, double-blind placebo-controlled study. $J$ Eur Acad Dermatology Venereol. 2011;25(12):1402-1408. doi:10.1111/j.1468-3083.2011.03984.x

82. Al-Mutairi N, Abdalla TO, Nour TM. Resistant palmoplantar lesions in patients of psoriasis: evaluation of the causes and comparison of the frequency of delayed-type hypersensitivity in patients without palm and sole lesions. Med Princ Pract. 2014;23 (6):561-567. doi:10.1159/000365573 
83. Adıșen E, Tekin O, Gülekon A, Gürer M. A retrospective analysis of treatment responses of palmoplantar psoriasis in 114 patients. $J$ Eur Acad Dermatology Venereol. 2009;23(7):814-819. doi:10.1111/j.1468-3083.2009.03197.x

84. Chalmers R, Hollis S, Leonardi-Bee J, Griffiths CE, Marsland A. Interventions for chronic palmoplantar pustulosis. Cochrane Database Syst Rev. 2006. doi:10.1002/14651858.CD001433.pub2

85. Engin B, Oguz O. Evaluation of time-dependent response to psoralen plus UVA (PUVA) treatment with topical 8-methoxypsoralen (8-MOP) gel in palmoplantar dermatoses. Int J Dermatol. 2005;44 (4):337-339. doi:10.1111/j.1365-4632.2004.02153.x

86. Carrascosa JM, Plana A, Ferrándiz C. Effectiveness and Safety of Psoralen-UVA (PUVA) topical therapy in palmoplantar psoriasis: a report on 48 patients. Actas Dermo-Sifiliográficas (English Ed. 2013;104(5):418-425. doi:10.1016/j.adengl.2013.04.005

87. Esen Salman K. The efficacy and safety of targeted narrowband UVB therapy: a retrospective cohort study. TURKISH J Med Sci. 2019;49(2):595-603. doi:10.3906/sag-1810-110

88. Su L, Ren J, Cheng S, Liu J, Ding Y, Zhu N. UVA1 vs. narrowband UVB phototherapy in the treatment of palmoplantar pustulosis: a pilot randomized controlled study. Lasers Med Sci. 2017;32(8):1819-1823. doi:10.1007/s10103-017-2280-0

89. Nisticò SP, Saraceno R, Schipani C, Costanzo A, Chimenti S. Different applications of monochromatic excimer light in skin diseases. Photomed Laser Surg. 2009;27(4):647-654. doi:10. 1089/pho.2008.2317

90. Ettler K, Richards B. Acitretin therapy for palmoplantar pustulosis combined with UVA and topical 8-MOP. Int $J$ Dermatol. 2001;40(8):541-542. doi:10.1046/j.1365-4362.2001.01094-3.x

91. Matsunami E, Takashima A, Mizuno N, Jinno T, Ito H. Topical PUVA, Etretinate, and Combined PUVA and etretinate for palmoplantar pustulosis: comparison of therapeutic efficacy and the influences of tonsillar and dental focal infections. J Dermatol. 1990;17(2):92-96. doi:10.1111/j.1346-8138.1990.tb03713.x

92. Reich K, Graff O, Mehta N. Oral alitretinoin treatment in patients with palmoplantar pustulosis inadequately responding to standard topical treatment: a randomized Phase II study. Br J Dermatol. 2016;174(6):1277-1281. doi:10.1111/bjd.14401

93. Brunasso AMG, Massone C. Alitretinoin therapy for palmoplantar pustulosis. Br J Dermatol. 2017;177(2):578-579. doi:10.1111/ bjd. 15605

94. Navarro R, Daudén E. Reacciones psoriasiformes paradójicas durante el tratamiento con terapia anti-factor de necrosis tumoral. Manejo clínico. Actas Dermosifiliogr. 2014;105(8):752-761. doi:10.1016/j.ad.2013.05.007

95. Gerdes S, Franke J, Domm S, Mrowietz U. Ustekinumab in the treatment of palmoplantar pustulosis. Br J Dermatol. 2010;163 (5):1116-1118. doi:10.1111/j.1365-2133.2010.09897.x
96. Bertelsen T, Kragballe K, Johansen C, Iversen L. Efficacy of ustekinumab in palmoplantar pustulosis and palmoplantar pustular psoriasis. Int $J$ Dermatol. 2014;53(10):e464-e466. doi:10.1111/ijd.12511

97. Morales-Múnera C, Vilarrasa E, Puig L. Efficacy of ustekinumab in refractory palmoplantar pustular psoriasis. $\mathrm{Br} J$ Dermatol. 2013;168(4):820-824. doi:10.1111/bjd.12150

98. Au S-C, Goldminz AM, Kim N, et al. Investigator-initiated, open-label trial of ustekinumab for the treatment of moderate-tosevere palmoplantar psoriasis. J Dermatolog Treat. 2013;24 (3):179-187. doi:10.3109/09546634.2012.672710

99. Pinto-Almeida T, Torres T, Sanches M, Selores M. Treatment of palmoplantar pustulosis with ustekinumab - the importance of interfering with the IL23/Th17 pathway. Eur J Dermatol. 2013;23 (6):916-917. doi:10.1684/ejd.2013.2196

100. Nogueira M, Torres T. Guselkumab for the treatment of psoriasis evidence to date. Drugs Context. 2019;8:1-11. doi:10.7573/ dic. 212594

101. Terui T, Kobayashi S, Okubo Y, Murakami M, Hirose K, Kubo H. Efficacy and safety of guselkumab, an anti-interleukin 23 monoclonal antibody, for palmoplantar pustulosis. JAMA Dermatol. 2018;154(3):309. doi:10.1001/jamadermatol.2017.5937

102. Blauvelt A, Papp KA, Griffiths CEM, et al. Efficacy and safety of guselkumab, an anti-interleukin-23 monoclonal antibody, compared with adalimumab for the continuous treatment of patients with moderate to severe psoriasis: results from the phase III, double-blinded, placebo- and active comparator. $J$ Am Acad Dermatol. 2017;76(3):405-417. doi:10.1016/j.jaad.2016.11.041

103. Torres T, Puig L. Apremilast: a novel oral treatment for psoriasis and psoriatic arthritis. Am J Clin Dermatol. 2018;19(1):23-32. doi:10.1007/s40257-017-0302-0

104. Li H, Zuo J, Tang W. Phosphodiesterase-4 inhibitors for the treatment of inflammatory diseases. Front Pharmacol. 2018;9. doi:10.3389/fphar.2018.01048

105. Skov L, Beurskens FJ, Zachariae COC, et al. IL-8 as antibody therapeutic target in inflammatory diseases: reduction of clinical activity in palmoplantar pustulosis. $J$ Immunol. 2008;181 (1):669-679. doi:10.4049/jimmunol.181.1.669

106. Ganesan R, Raymond EL, Mennerich D, et al. Generation and functional characterization of anti-human and anti-mouse IL-36R antagonist monoclonal antibodies. MAbs. 2017;9(7):1143-1154. doi:10.1080/19420862.2017.1353853

107. Cornelius V, Wilson R, Cro S, et al. A small population, randomised, placebo-controlled trial to determine the efficacy of anakinra in the treatment of pustular psoriasis: study protocol for the APRICOT trial. Trials. 2018;19(1):465. doi:10.1186/s13063-0182841-y
Clinical, Cosmetic and Investigational Dermatology is an international, peer-reviewed, open access, online journal that focuses on the latest clinical and experimental research in all aspects of skin disease and cosmetic interventions. This journal is indexed on CAS.
The manuscript management system is completely online and includes a very quick and fair peer-review system, which is all easy to use. Visit http://www.dovepress.com/testimonials.php to read real quotes from published authors. 